\title{
Overlapping Neural Substrates of Alcohol- and Anxiety-Related Behaviors in the Rat
}

Riccardo Barchiesi

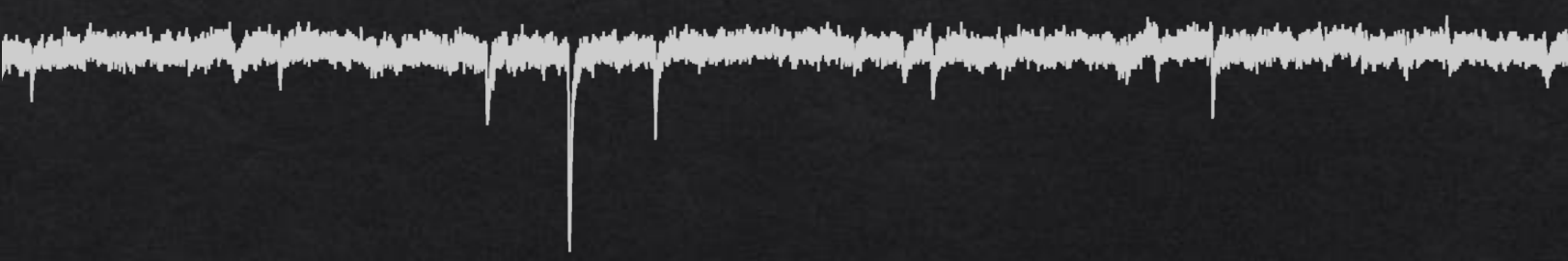





\title{
Overlapping Neural Substrates of Alcohol- and Anxiety-Related Behaviors in the Rat
}

\author{
Riccardo Barchiesi
}

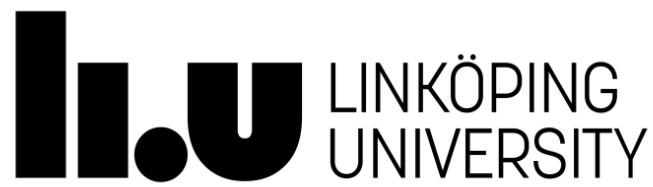

Center for Social and Affective Neuroscience Department of Biomedical and Clinical Sciences

Faculty of Medicine and Health Sciences, Linköping University

SE-58183 Linköping, Sweden

Linköping 2021 


\section{$($ (c) EYYNG NonCommercial 4.0 International License. \\ https://creativecommons.org/licenses/by-nc/4.0/}

Copyright (C) Riccardo Barchiesi, 2021

Published papers I and III are open access articles and the authors retain the copyright ownership

ISBN: 978-91-7929-741-1

ISSN: 0345-0082

Cover: representative traces of spontaneous excitatory postsynaptic currents recorded (by Michele Petrella) in principal BLA neurons following Prmd 2 knock-down (back) and scrambled control (front)

Printed in Linköping by Linköpings Tryckeri AB, March 2021 


\section{SUPERVISOR}

\section{Estelle Barbier, Docent}

Department of Biomedical and Clinical Sciences Linköping University, Sweden

\section{CO-SUPERVISORS}

Markus Heilig, Professor, MD PhD

Department of Biomedical and Clinical Sciences Linköping University, Sweden

Annika Thorsell, Docent

Department of Biomedical and Clinical Sciences Linköping University, Sweden 


\section{ABSTRACT}

Alcohol use is a leading cause of death and disease worldwide. A large part of this disease burden is associated with alcohol use disorder (AUD), a diagnostic category characterized by excessive use in spite of negative consequences ("compulsive use"), a loss of control over intake, and choice of alcohol over natural rewards. These behavioral symptoms are believed to reflect the emergence of persistent neuroadaptations in key brain regions that exert control over motivated behavior. A major challenge to addressing the treatment needs of patients with AUD is the high prevalence of co-occurring psychiatric disorders, of which anxiety disorders are the most common. Both AUD and anxiety disorders are characterized by broad changes in gene expression within brain regions that include the prelimbic cortex (PL) and the amygdala complex. Although the risk for AUD has a substantial genetic component, heavy alcohol use and stress also contribute to disease risk.

Our lab previously identified DNA hypermethylation as a mechanism behind alcohol-induced downregulation of prelimbic Syt1 and Prdm2. In a subsequent study, our lab demonstrated a functional role of Prdm2 in alcohol-associated behaviors. In the work that constitutes this thesis, we have further investigated the behavioral consequences of Syt1 and Prdm2 downregulation. We found that Syt1 knock-down in the PL of non-dependent rats is sufficient to promote several behaviors that model critical aspects of AUD. We further identified the PL-basolateral amygdala (BLA) projection as a key brain circuit within which Syt1 knock-down promotes compulsive-like alcohol intake. In another study, we showed that Prdm2 knock-down in the PL increases the expression of fear memory, a central feature of anxiety disorders. Knock-down after memory formation (consolidation) did not increase the fear expression, indicating that Prdm2 regulates fear memory consolidation. We further showed that knock-down of Prdm2 in the PL-BLA projection was sufficient to promote the increased fear expression. Transcriptome analysis specifically in neurons projecting from the PL to the BLA showed a marked up-regulation of genes involved in synaptogenesis, suggesting that Prdm2 downregulation leads to excessive fear by strengthening fear memory consolidation in the PL-BLA circuit.

In a third study, we used a model of social defeat- and witness stress to investigate mechanisms of cooccurring escalated alcohol intake and increased anxiety-like behavior ("comorbidity"). We recapitulated the broad range of individual stress responses observed in human populations. With gene expression analysis, we identified a marked upregulation of Avp in the amygdala of rats with "comorbid" characteristics, and this upregulation correlated with the magnitude of the comorbidity.

Together, our findings highlight the contribution of epigenetic mechanisms in regulating the behavioral consequences of alcohol-dependence, and identify specific downstream target genes whose expression is influenced by alcohol-induced epigenetic reprogramming to mediate long-term behavioral consequences. Our work also identifies amygdala Avp as a possible neurobiological substrate of individual susceptibility for stress-induced alcohol- and anxiety-related behaviors. 


\section{POPULÄRVETENSKAPLIG SAMMANFATTNING}

\section{GEMENSAMMA MEKANISMER FÖR ALKOHOL- OCH ÅNGESTRELATERADE BETEENDEN STUDERADE I DJURMODELLER}

Alkoholbruk är en av huvudorsakerna till den globala sjukdomsbördan, och står för ungefär 5 \% av alla dödsfall i världen. Sjukdomsbördan från alkohol orsakas till stor del av alkoholberoende, en komplex psykiatrisk sjukdom som kännetecknas av kontrollförlust, val av alkohol framför naturliga belöningar, och fortsatt bruk trots negativa konsekvenser (så kallat "kompulsivt bruk"). Dessa beteenden tros avspegla långvariga förändringar i funktionen hos hjärnstrukturer som styr motiverade beteenden. Av alla individer som brukar alkohol är det endast en minoritet, ca $15 \%$, som utvecklar alkoholberoende. Kända riskfaktorer inkluderar ärftlighet, mängd alkohol som konsumeras och stress. Behandlingar som finns tillgängliga för patienter med alkoholberoende har i dagsläget en otillräcklig effekt. För att utveckla nya läkemedel är det viktigt att förstå mekanismer som ligger bakom utveckling och vidmakthållande av beroende.

Övergången från rekreationsbruk till beroende sker genom flera mekanismer. Likt andra droger kan alkohol aktivera hjärnans belöningssystem, och man tror att konsumtionen i tidigare stadier drivs av dessa "positivt förstärkande", eller belönande effekter. Utvecklingen av beroende avspeglar en förskjutning till ett tillstånd där bruket $\mathrm{i}$ allt högre grad sker för att dämpa negativa känslor (s.k. "negativ förstärkning"). Denna utveckling avspeglar att system i hjärnan som styr reaktioner på stress och upplevelser av oro och ångest blir aktiverade. En yttring av detta är att patienter med alkoholberoende ofta uppvisar en samsjuklighet med ångestsjukdomar. Patienter med samsjukligt alkoholberoende och ångest uppvisar ofta svårare symtom, och är mer svårbehandlade. Det finns idag ingen evidensbaserad behandling för dessa patienter. Stress är en viktig riskfaktor för både alkoholberoende och ångest, men det finns en betydande individuell variation i sårbarheten för stress.

Vi har tidigare visat att utveckling av alkoholberoende i en råttmodell leder till beteendeförändringar som liknar vad som ses hos patienter med alkoholberoende. I råttmodellen är dessa beteendeförändringar resultatet av en epigenetisk mekanism, dvs en mekanism som reglerar förändringar i genuttryck utan att DNA sekvensen ändras. Epigenetiska mekanismer påverkar uttrycket av många gener samtidigt, och kan bidra till förändringar i hjärnfunktion som ses vid alkohol- och ångestsjukdomar. Vi har tidigare identifierat två gener, Syt1 och Prdm2, som var nedreglerade i prelimbiska cortex efter alkoholberoende, en del av hjärnans pannlob som är viktig för exekutiva funktioner och planering för framtiden. Syt1 kodar för ett protein som är centralt för en nervcells förmåga att frisätta signalmolekyler och kommunicera med andra nervceller. Prdm2 kodar för ett epigenetiskt enzym som i sin tur reglerar uttrycket av flera andra gener. Vi visade sedan att nedreglering av Prdm2 var tillräckligt för att råttor utan tidigare alkoholberoende skulle bete sig som om de utvecklat beroende.

I den här avhandlingen visade vi att även Syt1-nedreglering kan efterlikna de beteendeförändringar som annars ses vid utveckling av alkoholberoende i råttor. Nedreglering av Syt1 specifikt i nervbanan från prelimbiska cortex till basolaterala amygdala var tillräcklig för effekten, vilket identifierar dessa nervceller som en viktig komponent $\mathrm{i}$ beroende-relaterade förändringar $\mathrm{i}$ hjärnfunktionen. Målområdet för denna nervbana, basolaterala amygdala, är en hjärnregion som man sedan tidigare vet är viktig för regleringen av känslor såsom rädsla och ångest. Vi kunde även visa att förändringarna sannolikt sker genom en minskad aktivitet i cellkroppar i prelimbiska cortex, vilket i sin tur leder till en ökad aktivitet i basolaterala amygdala. Detta stämmer med observationer hos patienter med 
alkoholberoende, hos vilka man ofta ser en så kallad hypofrontalitet, dvs att prefrontala cortex uppvisar en minskad aktivitet.

I en annan studie demonstrerade vi att även nedreglering av Prdm2 i prelimbiska cortex leder till ett ökat uttryck av rädslominnen, en central komponent $\mathrm{i}$ ångestsyndrom. Vi visade att förändringar $\mathrm{i}$ funktionen hos samma nervbana, projektionen från prelimbiska cortex till basolaterala amygdala, orsakade denna patologiska rädsla. Vi undersökte sedan genförändringar som orsakas av en Prdm2 nedreglering specifikt i dessa nervceller, och fann bl.a. att gener associerade med synapsbildning och kommunikation mellan nervceller var uppreglerade. Detta kan tolkas som en förstärkt inlärning av rädslominnen, som i sin tur leder till det ökade uttrycket av rädsla.

För att identifiera mekanismer som ligger till grund för samsjuklighet mellan alkoholberoende och ångestsyndrom använde vi oss av en modell med fysisk och emotionell social stress. Resultat från denna studie visade att endast en minoritet av råttor utsatta för endera stressen utvecklade både alkohol- och ångestrelaterade beteenden. Analys av genuttryck i amygdala identifierade en uppreglering av stresshormonet vasopressin endast i denna "samsjukliga" population av råttor, vilket indikerar att det skulle kunna vara en sårbarhetsfaktor för stressinducerade psykiatriska störningar. 


\section{LIST OF PAPERS}

This thesis is based on the following papers, referred to in the text by their Roman numerals:

\section{PAPER I}

Estelle Barbier*, Riccardo Barchiesi*, Ana Domi, Kanat Chanthongdee, Esi Domi, Gaëlle Augier, Eric Augier, Li Xu, Louise Adermark, Markus Heilig. *Authors contributed equally

Downregulation of Synaptotagmin 1 in the Prelimbic Cortex Drives Alcohol-Associated Behaviors in Rats

Biological Psychiatry 2021 Feb 15;89(4):398-406. https://doi.org/10.1016/j.biopsych.2020.08.027

\section{PAPER II}

Riccardo Barchiesi, Kanat Chanthongdee, Michele Petrella, Simon Söderholm, Esi Domi, Gaëlle Augier, Andrea Coppola, Joost Wiskerke, Eric Augier, Claudio Cantù, Markus Heilig, Estelle Barbier

Prdm2 modulates fear memory consolidation through neurons projecting from prelimbic cortex to the basolateral amygdala

Manuscript

\section{PAPER III}

Riccardo Barchiesi, Kanat Chanthongdee, Esi Domi, Francesco Gobbo, Andrea Coppola, Anna Asratian, Sanne Toivainen, Lovisa Holm, Gaëlle Augier, Li Xu, Eric Augier, Markus Heilig, Estelle Barbier

Stress-induced escalation of alcohol self-administration, anxiety-like behavior, and elevated amygdala Avp expression in a susceptible subpopulation of rats

Addiction Biology 2021 Feb 9;e13009 (e-pub ahead of print). https://doi.org/10.1111/adb.13009 


\section{TABLE OF CONTENTS}

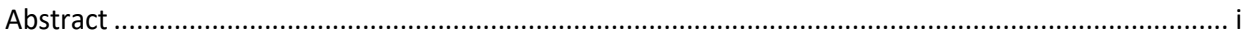

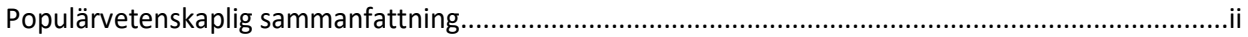

Gemensamma mekanismer för alkohol- och ångestrelaterade beteenden studerade i djurmodeller

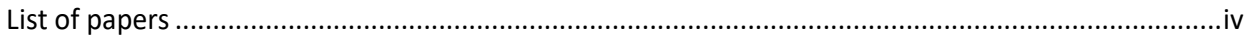

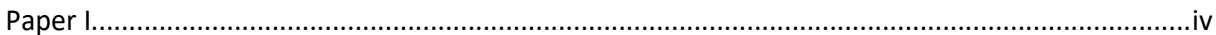

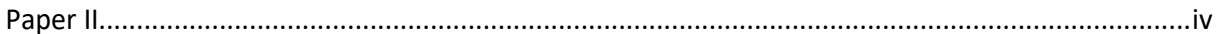

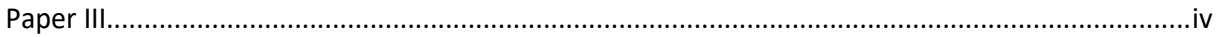

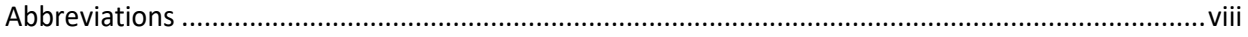

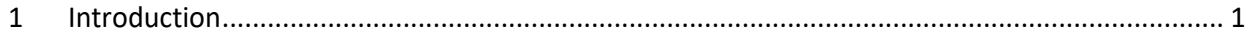

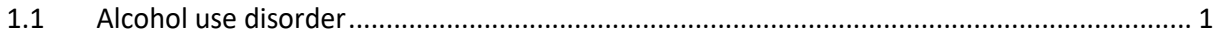

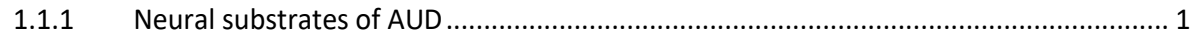

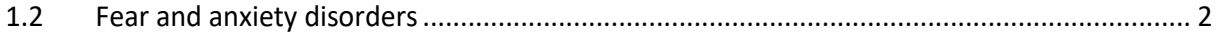

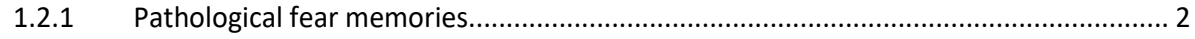

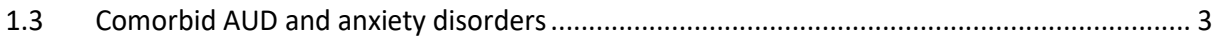

1.3.1 Etiology of comorbid AUD and anxiety disorders .............................................. 3

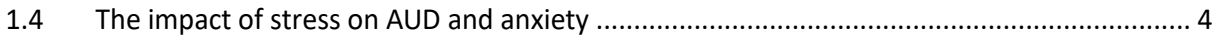

1.4.1 Individual variation in susceptibility and resilience to stress-induced psychopathology 4

1.5 Epigenetic mechanisms in AUD and anxiety disorders .................................................. 5

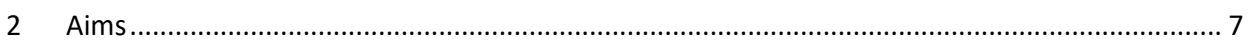

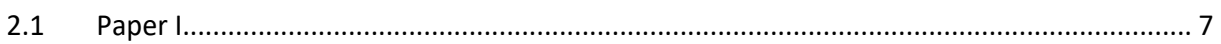

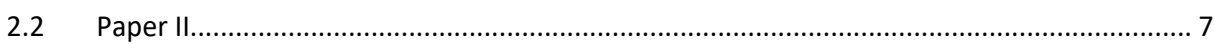

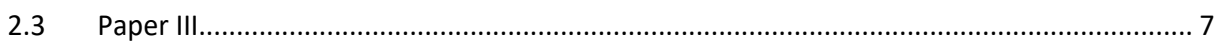

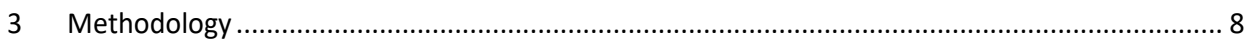

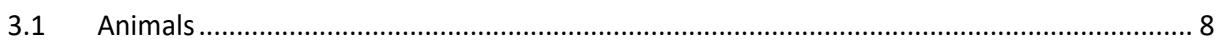

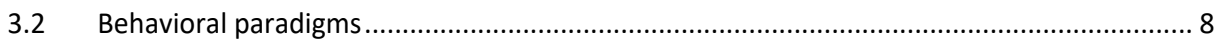

3.2.1 Alcohol self-administration ............................................................................... 8

3.2.2 Progressive ratio schedule of reinforcement ...................................................... 8

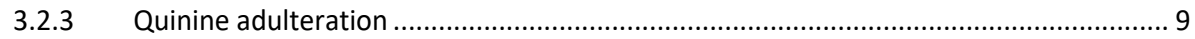

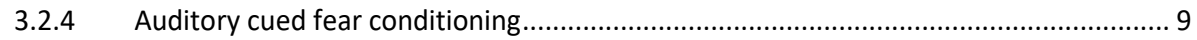

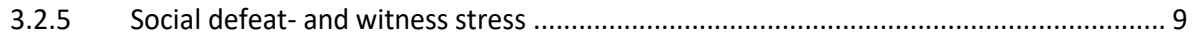

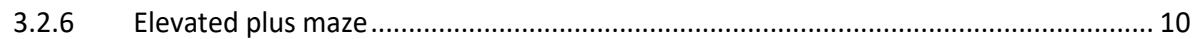

3.2.7 Controls for behavioral specificity ...................................................................... 10

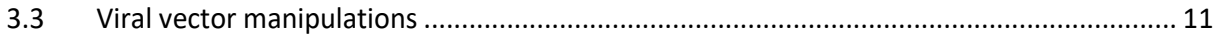




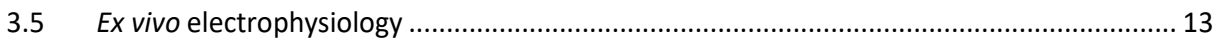

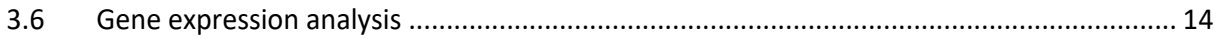

3.6.1 Projection Specific VTRAP-RNA sequencing ................................................. 14

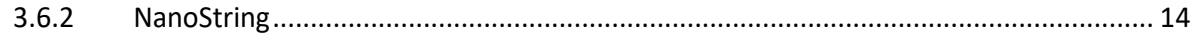

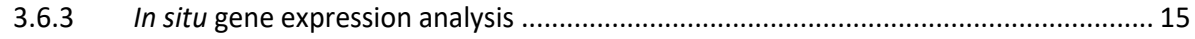

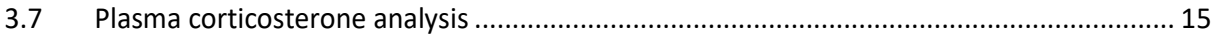

Experimental overview and timelines ............................................................... 15

3.8.1 Paper I: Downregulation of Synaptotagmin 1 in the prelimbic cortex drives alcohol

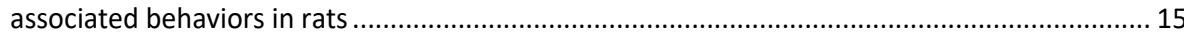

3.8.2 Paper II: Prdm2 modulates fear memory consolidation through neurons projecting from prelimbic cortex to the basolateral amygdala......................................................... 16

3.8.3 Paper III: Stress-induced escalation of alcohol self-administration, anxiety-like behavior, and elevated amygdala Avp expression in a susceptible subpopulation of rats

4 Results and discussion

4.1 Paper I: Downregulation of Synaptotagmin 1 in the prelimbic cortex drives alcohol

4.1.1 Prelimbic Syt1 knock-down promotes alcohol-addiction like behaviors .................... 18

4.1.2 Behavioral effects of Syt1 knock-down are specific for alcohol............................... 18

4.1.3 Syt1 knock-down reduces neural excitability in the PL ........................................... 18

4.1.4 Syt1 knock-down in neurons projecting from the PL to the BLA promotes compulsive-

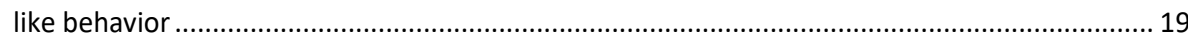

4.1.5 Syt1 knock-down increases neuronal excitability in the BLA .................................... 19

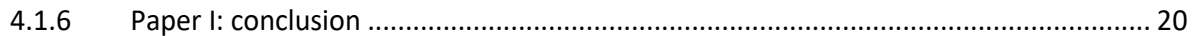

4.2 Paper II: Prdm2 modulates fear memory consolidation through projections from the prelimbic cortex to the basolateral amygdala.....

4.2.1 Prdm2 knock-down in the PL causes a long-lasting increase in fear expression by modulating memory consolidation .................................................................................. 20

4.2.2 Effects of Prdm2 knock-down are specific for fear memories ................................... 20

4.2.3 Prdm2 knock-down in projections from the PL to the BLA are sufficient to promote

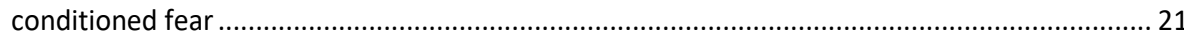

4.2.4 Prdm2 knock-down in the PL results in increased neuronal activity in the BLA .......... 21

4.2.5 Knock-down of Prdm2 modulates the expression of genes involved in synaptogenesis

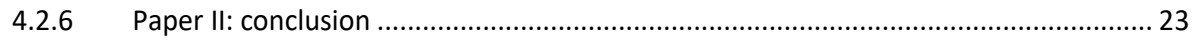

4.3 Paper III: Stress-induced escalation of alcohol self-administration, anxiety-like behavior, and elevated amygdala Avp expression in a susceptible subpopulation of rats....

4.3.1 Social defeat- and witness stress induce persistent comorbid anxiety-like behavior and escalation of alcohol self-administration in a susceptible subpopulation of rats...... 
4.3.2 Association between AMG gene expression, stress type, and behavioral characteristics

4.3.3 Amygdala Avp correlates with the magnitude of comorbidity ...................................... 25

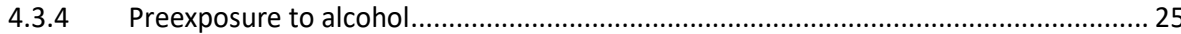

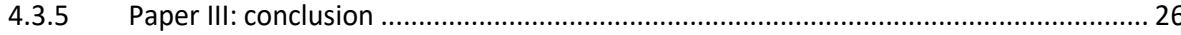

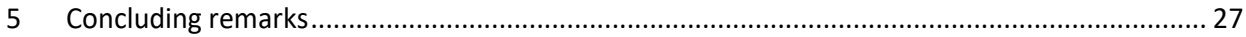

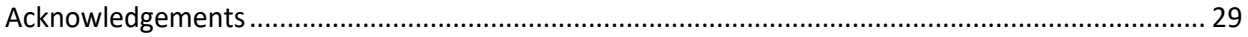

6 References 


\section{ABbREVIATIONS}

$\begin{array}{ll}\text { AAV } & \text { adeno-associated viruses } \\ \text { AMG } & \text { amygdala complex } \\ \text { AUD } & \text { alcohol use disorder } \\ \text { AUC } & \text { area under the curve } \\ \text { Avp/AVP } & \text { vasopressin (gene/protein) } \\ \text { BLA } & \text { basolateral amygdala } \\ \text { CaM } & \text { calmodulin } \\ \text { CI } & \text { comorbidity index } \\ \text { CS } & \text { conditioned stimulus } \\ \text { DIO } & \text { double-floxed inverted open reading frame } \\ \text { DNMT } & \text { DNA methyltransferase } \\ \text { DSM } & \text { diagnostic and statistical manual of mental disorders } \\ \text { EGFP } & \text { enhanced green fluorescent protein } \\ \text { EPM } & \text { elevated plus maze } \\ \text { FR } & \text { fixed ratio } \\ \text { HAT } & \text { histone acetyltransferase } \\ \text { HDAC } & \text { histone deacetylase } \\ \text { HPA-axis } & \text { hypothalamic-pituitary-adrenal } \\ \text { miRNA } & \text { microRNA } \\ \text { mPFC } & \text { medial prefrontal cortex } \\ \text { NAC } & \text { nucleus accumbens } \\ \text { NOR } & \text { novel object recognition } \\ \text { Oxt/OXT } & \text { oxytocin (gene/protein) } \\ \text { PFC } & \text { prefrontal cortex } \\ \text { PL } & \text { prelimbic cortex } \\ \text { PR } & \text { progressive ratio } \\ \text { Prdm2/PRDM2 } & \text { PR domain containing 2 (gene/protein) } \\ \text { PTSD } & \text { post-traumatic stress disorder } \\ \text { SDS } & \text { social defeat stress } \\ \text { ShRNA } & \text { short hairpin RNA } \\ \text { siRNA } & \text { small interfering RNA } \\ \text { Syt1/SYT1 } & \text { synaptotagmin } 1 \text { (gene/protein) } \\ \text { US } & \text { unconditioned stimulus } \\ \text { VTRAP } & \text { virasomal affinity purification } \\ & \end{array}$




\section{INTRODUCTION}

\subsection{ALCOHOL USE DISORDER}

Alcohol use accounts for $5.3 \%$ of all deaths and $5.1 \%$ of the global disease burden, making it a major public health problem ${ }^{1}$. The disease burden of alcohol is in large part associated with alcohol use disorder (AUD), a diagnostic category which in its moderate and severe forms can be equated with alcohol addiction, or simply "alcoholism". AUD is a complex psychiatric disorder characterized by loss of control over intake, choice of alcohol over natural rewards, and excessive use despite negative consequences ("compulsive use"). These behavioral symptoms are thought to reflect the emergence of persistent neuroadaptations in key brain structures that exert control over motivated behavior ${ }^{2-4}$.

Alcohol use becomes disordered through multiple mechanisms. Similar to other addictive drugs, alcohol can activate classical brain reward systems, and during early, recreational stages, alcohol use is primarily thought to be positively reinforced, i.e. consumed for the resulting pleasurable effects ${ }^{5-7}$. Progression into later stages of AUD is associated with a transition to a relief-driven (negatively reinforced) alcohol seeking and intake, in which neural systems that mediate stress and anxiety become increasingly recruited ${ }^{8}$. Only a minority, or approximately $15 \%$ of regular alcohol users develop AUD ${ }^{9}$. Known risk factors include genetics, pattern of drinking (binge), amount of alcohol consumed, early-life trauma and stress ${ }^{10}$.

The prevalence of AUD is higher in men than in women, and males account for more of the total alcohol-related harm than females, including deaths ${ }^{11}$. Although distinct sex-differences in the reinforcing effects of alcohol have been observed ${ }^{12}$, the gap in the prevalence of AUD between men and women has decreased over time, indicating that cultural norms contribute to the sex differences in alcohol use and AUD. Women have a higher co-occurrence of AUD and anxiety disorders ${ }^{13}$, and are more likely to cite negative emotions and stressful life experiences as reasons for substance use and relapse, suggesting that women may be more likely to rely on alcohol to manage anxiety ${ }^{14,15}$.

Three classes of pharmacological treatments are currently approved by the American Food and Drug Administration (FDA). These include the acetaldehyde dehydrogenase-inhibitor disulfiram, the mupreferring opioid receptor antagonist naltrexone, and acamprosate, which exerts its effects through glutamatergic mechanisms that are presently not fully understood. Additional medications that are not approved for treatment of AUD but have marketing approval for other indications have shown efficacy and are used off-label. These include the GABAB receptor agonist baclofen which is approved for treatment of spasticity, the ion channel blocker topiramate that is approved for treatment of epilepsy, and the partial nicotinic receptor agonist varenicline that is an approved smoking cessation treatment ${ }^{16}$. The efficacy of available drugs needs to be improved, and a broader range of therapeutic mechanisms may increase opportunities for personalized treatments.

\subsubsection{Neural substrates of AUD}

\subsubsection{Positively reinforcing properties of alcohol ("reward")}

As indicated above, alcohol can exert positively reinforcing ("rewarding") effects, thought to occur through the activation of classical brain reward systems, and ultimately resulting in activation of dopamine (DA) release from terminals of mesolimbic DA neurons in the nucleus accumbens (NAC). Alcohol-induced activation of this system is in part thought to reflect a cascade in which alcohol intake activates the release of endogenous opioids from neurons originating in the lateral hypothalamus that project to the VTA. Within the VTA, this results in opioid receptor activation on inhibitory GABA-ergic interneurons, removal of inhibitory GABA-ergic tone from mesolimbic DA neurons, and ultimately DA 
release in terminal areas in the ventral striatum $/ \mathrm{NAc}^{17}$. Accordingly, subjective reports of intoxication in healthy male volunteers correlate with ventral striatal activation and DA-release ${ }^{6,12}$.

\subsubsection{Negatively reinforcing properties of alcohol ("relief")}

Negatively reinforcing ("relief-providing") properties of alcohol emerge through persistent changes in brain function, or "neuroadaptations", that result in a progressive recruitment of brain systems that mediate stress- and fear-responses. Although less well understood, these neuroadaptations include chronic dysregulation of function within the amygdala complex, a key node of stress, fear and negative emotionality ${ }^{18,19}$.

\subsubsection{Executive cognitive function and top-down control}

Drugs and drug-associated cues elicit incentive motivation, but their impact on behavior is ultimately modulated by executive cognitive functions that are in large part mediated by prefrontal cortex (PFC). Addictive disorders including AUD are associated with deficit in these functions, such as impaired ability to inhibit prepotent responses, or a steep discounting of rewards that are distant in time ${ }^{20}$. Within the PFC, the prelimbic cortex (PL) exerts top-down regulation of subcortical regions including the BLA and the $\mathrm{NAC}^{4,21,22}$. PL projections to these regions have been implicated in control of drinking behaviors ${ }^{23,24}$.

\subsection{FEAR AND ANXIETY DISORDERS}

Fear is an adaptive response that allows the organism to escape life-threatening events. It can be innate or acquired (learned). Reciprocal connections between the amygdala and the medial PFC (mPFC) play a key role in both innate and learned fear. This core circuitry interacts with other brain regions, such as the periaqueductal grey and hippocampus, for assessing, remembering, and responding to threats ${ }^{25}$.

When fear becomes excessive, persists beyond what is adaptive or both, the result is an anxiety disorder. Anxiety disorders constitute the largest group of mental disorders worldwide, with lifetime prevalence rates of up to $30 \%$. They are characterized by excessive and enduring fear, and anxiety or avoidance of stimuli that do not in fact signal danger. Risk factors for anxiety disorders include genetics and stress, although disorder-specific risk factors have also been identified ${ }^{25}$.

\subsubsection{Pathological fear memories}

After a fear memory is acquired through association of specific sensory stimuli with the threatening or traumatic event, it undergoes consolidation. This refers to the process in which the information is stabilized, resulting in the storage of enduring memories. Subsequently, when a stimulus is encountered that serves as a reminder of the threat, these memories are retrieved, resulting in expression of species-specific fear responses, such as avoidance or freezing. Over time, when threatassociated stimuli are repeatedly experienced in the absence of a threat or harm, extinction takes place, wherein the fear memory is suppressed. This is thought to occur through new learning, resulting in a new memory indicating that the previously threat-associated stimulus is no longer signals threat, and is thus safe $\mathrm{e}^{26}$.

Excessive fear reflects an exaggerated activity and hyperexcitability of the neural circuits that subserve fear responses. These can become independent of the triggering stimuli, and promote fear responses even in the absence of relevant threats ${ }^{25,27}$. Excessive fear can be the result of an enhanced fear learning, impaired extinction, or generalization (impaired discrimination between cues). Impaired extinction and generalization of fear are both hallmarks of anxiety disorders, such as post-traumatic stress syndrome (PTSD) ${ }^{26}$. A schematic illustrating normal and pathological fear memory processing, 
along with factors that are known to promote pathological fear and development of anxiety disorders, is given in figure 1.

\section{Genes \\ DODOODODODOD}

Epigenetics Neurochemistry

$\longleftarrow$ Early life stress

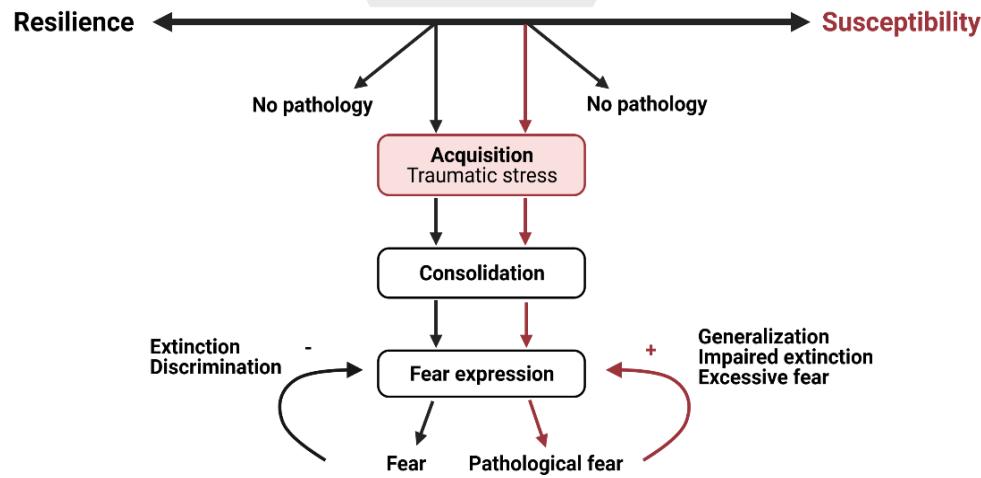

Figure 1. Fear memory regulation. Genetic heritability and early-life stress account for a large portion of the susceptibility for developing anxiety disorders. Epigenetic mechanisms contribute to this gene $x$ environment interaction. Following the acquisition of a fear memory (trauma), consolidation stabilizes the memory to a more permanent state. Upon being presented with a reminder of the threat, the fear memory is retrieved, resulting in fear expression. Repeated exposures to threatassociated stimuli in absence of the actual threat will result in extinction of the fear memory. In a minority of individuals that are more vulnerable to the stress (red arrows), fear memory processes become dysregulated, resulting in excessive and/or generalized fear - hallmarks of anxiety disorders.

\subsection{COMORBID AUD AND ANXIETY DISORDERS}

A major challenge to addressing the treatment needs of people with AUD is the high prevalence of cooccurring psychiatric conditions, with anxiety disorders being among the most common of these comorbidities. Patients with comorbid AUD and anxiety disorders often have more severe symptoms and poorer treatment outcomes, than patients with either of the conditions ${ }^{28}$. Currently, no evidencebased treatment exists specifically for this population.

\subsubsection{Etiology of comorbid AUD and anxiety disorders}

Three common models attempt to explain why AUD and anxiety disorders are frequently comorbid.

The self-medication model posits that people consume alcohol to cope with anxiety disorders, which leads to co-occurring AUD ${ }^{29}$. When people with comorbid AUD and anxiety disorders are queried about their drinking, they typically support purposeful and targeted drinking to cope with their anxiety. The reported rates of self-medication in clinical samples of people with both types of disorders have ranged from 50 to 97 percent, with the highest rates among people with phobias ${ }^{30-32}$.

The substance induced pathway posits, in apparent contrast to the self-medication model, that heavy alcohol use instead promotes the development of anxiety disorders, for instance through mechanisms of GABA deficiency and withdrawal-induced hyperexcitability ${ }^{15}$. Although this view is often considered to be in opposition to the self-medication model, the two are not necessarily mutually exclusive, and could both interact in what ultimately becomes a vicious cycle. 
The common factor model considers the role of a third variable that promotes both the risk of anxiety disorders and AUD, thus explaining the much higher-than-chance co-occurrence of these two conditions. This view is potentially supported by a 21-year longitudinal study found that anxiety disorders as a risk factor for AUD disappeared when all other things were controlled for (depression, prior drug dependence etc.) $)^{33}$.

\subsection{THE IMPACT OF STRESS ON AUD AND ANXIETY}

Substantial evidence links stress exposure to the development of both AUD and anxiety disorders. The prototypical example is PTSD, which develops following exposure to traumatic events ${ }^{34}$, and is highly comorbid with $A \cup D^{35}$. In addition to experiencing a traumatic event firsthand, observing others in fear or pain is also a form of psychological stress that can lead to the development of PTSD, and possibly also AUD. Although causality is difficult to infer from cross-sectional studies, professionals with high rates of occupational exposure to traumatic events, such as aid workers, trauma nurses and firefighters have an elevated risk of developing both anxiety disorders ${ }^{36}$ and $A U D^{37,38}$. One study in war veterans further found that perceived threat was more important for the development of PTSD than having experienced the traumatic event firsthand ${ }^{39}$. Together, this indicates the importance of psychological stress.

The relationship between stress and alcohol is bi-directional and complex. It is well known that vulnerability to stress is a risk factor for AUD. On the other hand, chronic alcohol use can result in neuroadaptations in stress-related brain pathways, and in hypothalamic-pituitary-adrenal (HPA) axis function ${ }^{40,41}$. These complex effects can be manifested in changes in behavior and cognitive control functions that contribute to alcohol craving and compulsive use $\mathrm{e}^{40,41}$. Exposure of the brain to alcohol also influences mechanisms that subserve fear learning. For example, in mice, chronic intermittent ethanol exposure was shown to remodel the dendritic arbor of the mPFC and impair fear extinction ${ }^{42}$.

Social stress is one of the most common stressors experienced by humans, and a significant risk factor for both $A \cup D^{43-46}$ and anxiety disorders ${ }^{47}$. In rodents, social stress has been modeled using social defeat stress $(S D S)^{48,49}$, which mimics aspects of social stress in humans that results from exposure to aggression and chronic subordination ${ }^{50}$. The SDS paradigm is based on social hierarchy and dominance, where the "defeated" animal is exposed to attacks and subsequent subordination by a conspecific ${ }^{51}$. Several studies report a causal role of SDS in the development of anxiety- and depression-like behaviors ${ }^{52-54}$, which can then persist for several weeks after the stress exposure ${ }^{48,55}$. The effect of SDS on alcohol consumption is less consistent, although some studies have reported an escalated intake $\mathrm{e}^{56}$.

1.4.1 Individual variation in susceptibility and resilience to stress-induced psychopathology

Although stress is an established risk factor for psychiatric disorders, only a minority of people who are directly exposed to, or witness a traumatic event develop a psychiatric disorder ${ }^{57}$. About $90 \%$ of all people are exposed to a significant traumatic event in their lifetime, but the lifetime prevalence of PTSD is "only" in the range 5-10\%. Among those who do develop PTSD, approx. 40-50\% also develop $A U D^{58}$. This points to the importance of understanding neural substrates of individual variation in susceptibility and resilience to stress, and suggests that mechanisms underlying vulnerability to anxiety disorders and AUD overlap. However, little is currently known about the neurobiological basis of individual differences in emotional stress responses, and even less about the molecular mechanisms behind stress-induced comorbid AUD and anxiety disorders. 


\subsection{EPIGENETIC MECHANISMS IN AUD AND ANXIETY DISORDERS}

"Epigenetic" refers to persistent regulation of gene expression that occurs in the absence of changes to the DNA sequence. This regulation is mediated by epigenetic enzymes that modify the availability of the gene for the transcriptional machinery.

A fundamental form of epigenetic regulation occurs through methylation of $\mathrm{CpG}$-dinucleotides (i.e. sequence elements where a cytosine is followed by a guanine) in a DNA strand by a class of enzymes called DNA-methyltransferases (DNMT:s). DNMT:s can either de novo methylate DNA, which is primarily performed by DNMT3, or they can participate in the maintenance of DNA methylation, which is performed by DNMT1, and in some cases DNMT3 ${ }^{59}$.

DNMT:s act in concert with mechanisms that modify histone proteins to which the DNA is bound. Multiple modifications can either be placed directly on the DNA (methylation), or on specific amino acids, most commonly lysine, within histone tails (e.g. acetylation and methylation). Three main classes of histone modifying enzymes exist. "Writer" enzymes, such as histone methyltransferases and histone acetyltransferases, add modifications, or "marks". "Reader" enzymes recognize these specific marks without modifying them, such as bromo domains, while "eraser" enzymes remove modifications. Depending on which epigenetic marks are dominant, the nucleosomes will become more or less condensed. The condensed form, known as heterochromatin, renders the gene inaccessible for the transcriptional machinery and the open form, called euchromatin, is instead associated with gene transcription. An overview of these mechanisms is given in figure 2, along with some known repressive/enhancing marks ${ }^{60}$.

Epigenetic enzymes have been implicated in translating environmental stimuli to changes in gene expression. They are also interesting treatment targets as they can simultaneously regulate the expression of multiple genes. Both AUD and anxiety disorders are characterized by broad and persistent changes in gene expression within brain areas involved in regulation of negative affect, such as the PL and the $\mathrm{AMG}^{61}$.

\section{Heterochromatin}

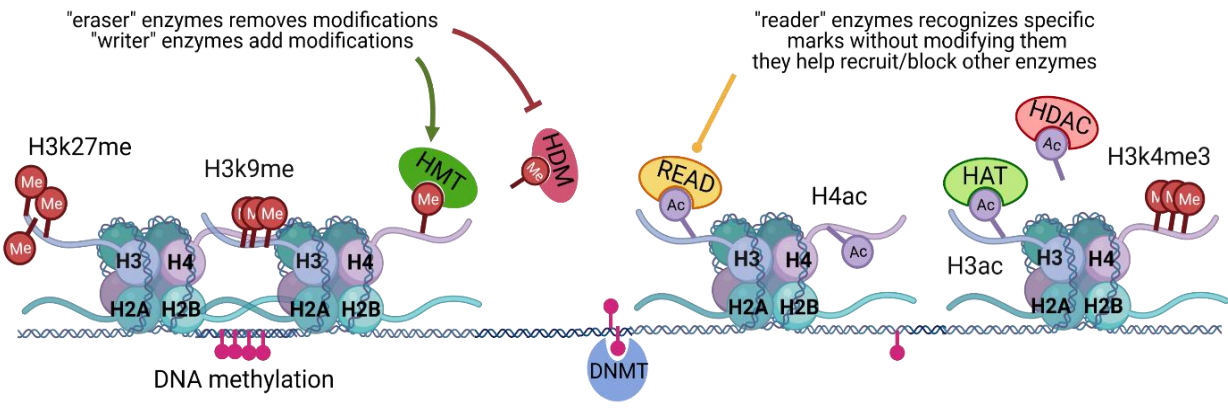

Figure 2. Epigenetic mechanisms regulate the availability of genes to the transcriptional machinery. In the heterochromatin state (left), DNA is tightly packed around the nucleosomes and is unavailable for transcription. In the euchromatin state (right), genes are instead available to the transcriptional machinery. Ac: acetyl group; DNMT: DNA methyltransferase; $H$ : histone; HAT: histone acetyltransferase; HDAC: histone deacetylase; HDM: histone demethylase; HMT: histone methyl transferase K: lysine; Me: methyl group.

Epigenetic mechanisms contribute to memory formation and consolidation in conditioned fear ${ }^{62}$. For example, inhibition of DNMT in the AMG resulted in an impairment of cued fear conditioning. This 
effect was rescued by a histone deacetylase inhibitor ${ }^{63}$, suggesting that histone-mediated mechanisms and DNA methylation work in concert to regulate conditioned fear memories. Substantial evidence also indicates a role of epigenetic mechanisms in anxiety-like behaviors that result from early-life stress $^{64,65}$. Dysregulation of epigenetic processes may therefore be one of the mechanisms that link traumatic stress exposure to the development of anxiety disorders ${ }^{66}$.

In our lab, we have demonstrated that a history of alcohol-dependence induces DNA hypermethylation of the MPFC in rats, and that reversing this using a DNMT inhibitor can partially rescue the behavioral consequences of alcohol-dependence ${ }^{67}$. A similar observation was made by Warnault et al., where systemic administration of a DNMT-inhibitor prevented escalation of alcohol intake following chronic intermittent alcohol exposure in mice ${ }^{68}$. More recently, we also demonstrated a role of the epigenetic enzyme PR domain containing 2, Prdm2, in alcohol associated behaviors ${ }^{69}$. Prdm2 is a histone methyltransferase that methylates lysine 9 on histone 3 (H3K9me), which is generally associated with transcriptional repression ${ }^{70,71}$. 


\section{AIMS}

The overall aim of this doctoral thesis was to investigate neural substrates of alcohol- and anxietyrelated behaviors in rats. Specifically, we aimed to address the following:

\subsection{PAPER I}

- Determine the role of Syt1 in alcohol addiction-like behaviors

- Identify neural circuits within which Syt1 acts to modulate these behaviors

We have previously found that Syt1 is downregulated in the PL in a rat model of alcohol addiction. Given the central role of Syt1 in synaptic transmission, we hypothesized that Syt1 downregulation may promote addiction-like behaviors.

\subsection{PAPER II}

- Determine the role of Prdm2 in conditioned fear memory

- Identify neural circuits within which Prdm2 acts to modulate this behavior, and investigate Prdm2-dependent transcriptomic changes in these circuits

We have previously demonstrated that prelimbic downregulation of $\mathrm{Prdm} 2$ promotes stress-induced relapse to alcohol seeking, suggesting a link between Prdm2 and stress regulation. We hypothesized that the role of Prdm2 in stress regulation extends beyond alcohol-associated behaviors, to other maladaptive behaviors such as excessive fear.

\subsection{PAPER III}

- Investigate molecular mechanisms underlying comorbid anxiety-like behavior and escalated alcohol intake. Specifically:

- To investigate mechanisms of individual variation in susceptibility and resilience to co-occurring stress-induced excessive fear and escalated alcohol taking

- To investigate whether physical and psychological stressors converge on similar mechanisms to promote these behaviors

AUD and anxiety are frequently comorbid, and stress is a well-established risk factor for both. We hypothesized that social defeat- and witness stress can induce co-occurring anxiety-like behavior and escalation of alcohol intake, and that only a subpopulation of rats will be susceptible to develop these behavioral consequences of stress. 


\section{Methodology}

\subsection{ANIMALS}

Adult male Wistar rats (200-225 g, Charles River, Germany) were used in Papers I-III. The Wistar rat is an outbred Albino rat that was originally developed in 1906 by the Wistar Institute ${ }^{72}$. It is one of the best characterized and widely used model organisms in biomedical research. Rats share a high genetic, anatomical, and physiological similarity with humans ${ }^{73}$, and their behavioral repertoire includes voluntary consumption of drugs of abuse ${ }^{74-76}$, fear responses $\mathrm{s}^{77,78}$ and social behaviors ${ }^{73,79}$. The Wistar rats show high individual variation in many behaviors. For example, like humans, they show a high individual variation in susceptibility and resilience to stress ${ }^{26,80,81}$. Their vulnerability to developing alcohol addiction-like behaviors has a distribution similar to that observed in humans ${ }^{82,83}$.

Rats were housed in groups of 2-4 under a reverse 12:12 h light cycle (lights on at 7 PM), in a humidityand temperature-controlled environment, and with free access to food and water. Rats were habituated to the facility and handled prior to the experiments. All behavioral experiments took place during the dark phase. Procedures were conducted in accordance with the National Committee for animal research in Sweden and approved by the Local Ethics Committee for Animal Care and Use at Linköping University.

\subsection{BeHAVIORAL PARADIGMS}

\subsubsection{Alcohol self-administration}

Operant self-administration is widely used for modelling drug taking in rodents ${ }^{84}$. After training, the animal is able to press a lever in order to voluntarily obtain the reward ${ }^{74,75}$. The intake can be quantified, and the number of reinforcers correlates with blood alcohol levels $\mathrm{s}^{75}$. The voluntary nature of this model is important, as it is associated with neuronal adaptations that are in part different from those found with passive administrations, such as injections ${ }^{85}$. While quantity of alcohol used is not a part of the diagnostic criteria in DSM- 5 per $s e^{86}$, it remains one of the key features associated with alcohol-related harm in epidemiological studies; the more alcohol that is consumed, the higher the risk of death and disease ${ }^{1,87}$. An escalated consumption may therefore reflect part of the neuroadaptations that promotes harmful alcohol use observed in AUD.

In brief, animals were trained for approximately one month to self-administer $20 \%$ alcohol under a fixed ratio 1 (FR1), followed by approximately one month of training under FR2 as previously described $^{75}$. The sessions were conducted under FR2 after stable baseline was established. Baseline was calculated as the average reinforcers of the last 5- or 3-days prior to testing (Paper I and III, respectively).

\subsubsection{Progressive ratio schedule of reinforcement}

A high motivation to seek and/or take alcohol is part of the diagnostic criteria for AUD ${ }^{86}$. Motivation to consume alcohol is commonly modelled in rodents using a progressive ratio (PR) schedule of reinforcement, where the progression of lever presses required to receive a reinforcer - in this case, a unit dose of alcohol - is incrementally increased until the animal stops to respond, referred to as "breakpoint" ${ }^{88}$. In Paper I, PR was performed as previously described ${ }^{75}$ and the breakpoint was defined 
as the last ratio completed before 30 minutes passed without completion of the next ratio. This is thought to reflect the motivation to obtain one reinforcer.

\subsubsection{Quinine adulteration}

Compulsivity is a key feature of AUD and is defined by alcohol use despite negative consequences. In rodents, this can be modelled as aversion-resistant alcohol intake, e.g. using quinine adulteration. Quinine is a bitter tastant that normally causes rats to decrease their consumption. Rats that do not decrease their consumption, or do so only at a higher quinine concentration, are thought to show compulsive-like behavior ${ }^{89}$. In Paper I, we used quinine adulteration during operant alcohol selfadministration. After alcohol self-administration became stable under FR2 schedule, increasing concentrations of quinine were added to the ethanol. Each quinine concentration was tested for three days and the average was used for statistical analysis. Resistance to quinine adulteration was assessed by measuring the percentage of decrease in alcohol rewards after addition of quinine.

\subsubsection{Auditory cued fear conditioning}

Excessive and lasting fear is a core feature of anxiety disorders. The underlying neurobiology is thought to be evolutionarily well conserved ${ }^{25,78}$. One commonly used way of modelling fear- and anxietyrelated behavior in rodents uses Pavlovian fear conditioning, where an aversive, unconditioned stimulus (US; e.g. foot shock) is associated with an initially neutral stimulus. Through the processes of associative learning, the latter then acquires some properties of the US, and becomes a conditioned stimulus (CS; e.g. a cue tone) ${ }^{90,91}$. By later exposing the rat to the CS only and assessing fear behaviors, such as freezing ${ }^{92}$, this paradigm allows the investigation into several components of fear learning. These include the acquisition, consolidation, expression, and extinction of the fear memory ${ }^{26,91}$. Fear conditioning is believed to occur where the pathways transmitting the CS and US converge ${ }^{91}$, where the experience will activate a neuronal population that then undergoes persistent molecular and/or physical changes to become an "engram"93,94. Formation of fear associations with discrete stimuli has been demonstrated to largely rely on the basolateral / lateral amygdala, while activity of both the amygdala complex and the PL is required to express conditioned fear responses upon subsequent presentation of the $\mathrm{CS}^{77,91,95}$.

In Paper II, we used a cued fear conditioning paradigm to investigate the effects of Prdm2 on fear memory. Rats were conditioned in either context A or B (counterbalanced), by exposing them to 6 trials consisting of $1 \mathrm{~mA}$ foot shocks associated with a $30 \mathrm{~s}$ cue tone. Rats were then tested for the expression of fear memory in the opposite context, $24 \mathrm{~h}, 1$ week, or $>1$ month after the conditioning session, by exposing them to the cue tones only, and assessing freezing behavior. Extinction was investigated by repeating the expression test over two more days. We also assessed context generalization by scoring the percentage time spent freezing during the first minute of exploration during the expression test. Fear expression was measured as percentage time spent freezing during the cue tones.

\subsubsection{Social defeat- and witness stress}

In Paper III, we used social defeat stress (SDS) and witness stress to investigate co-occurring ("comorbid") stress-induced escalation of alcohol consumption and anxiety-like behavior. The SDS model is an adaptation of the established mouse model and the "vicarious" stress model ${ }^{48,49,96-98}$.

The SDS is a resident-intruder paradigm that uses social conflict and inter-male hierarchy to produce physical and emotional stress. It is considered to have ethological and ecological validity, as repeated 
SDS generates persistent emotional stress without habituation ${ }^{99,100}$. It is also considered etiologically relevant, as social stressors play a major role in the onset of several psychiatric disorders in humans ${ }^{101}$. Similar to what is observed after traumatic stress in humans, SDS can generate a range of individual responses. This makes SDS a particularly useful model for investigating the mechanisms that underlie individual susceptibility to stress-induced psychiatric disorders.

In the SDS procedure, the intruder is placed in the home cage of a larger, aggressive, and dominant rat ("aggressor"). This exposure lasts for 5-10 min. As the intruder cannot escape during this time, it is forced into a submissive, often supine posture, emits distress calls, and displays defensive and fearrelated behaviors such as freezing ${ }^{92,100}$. After the SDS session, the intruder is placed behind a perforated divider. This allows continued exposure to the stress of the aggressor, but does so in the absence of physical contact, and reduces the risk of physical harm. The procedure is repeated daily for a period of up to 10 days (a.k.a. "chronic SDS"), after which rats are kept single-housed to avoid social buffering of the stress responses ${ }^{102}$. Shorter periods of social defeat are sufficient to produce physiological responses such as elevated corticosterone and decreased growth. However, repeated social defeat stress for 10 days is usually needed to induce robust and persistent effects on drug consumption, anxiety- and depression-like behavior ${ }^{100,103}$.

Similar to experiencing stressful events firsthand, witnessing others in distress can also lead to the development of psychiatric disorders, including anxiety disorders and $A_{U D}{ }^{37,38}$. Although rats rarely inflict physical harm on each other, the SDS paradigm is a combination of physical and emotional stress $^{100}$. To disentangle the emotional component from the combined physical and emotional stress of the SDS, a second rat can be made to witness the social defeat through a perforated divider. The witness can either be familiar with the "demonstrator" (intruder) or not. It has been shown that observers of familiar conspecifics in distress will exhibit greater fear learning ${ }^{104-109}$. In paper III, rats were exposed to SDS for $10 \mathrm{~min} /$ day for 10 days, and a former cage mate was used as witness. Aggressors were cohoused with females, as rats that are sexually experienced display stronger territorial and aggressive behaviours ${ }^{110}$. Females were ovariectomized ${ }^{111}$ to prevent pregnancies.

\subsubsection{Elevated plus maze}

The elevated plus maze (EPM) is an approach-avoidance conflict-based task for assessing anxiety-like behavior in rodents. It relies on the conflict between unconditioned fear of open spaces and motivation to explore the environment ${ }^{112,113}$. It was developed from the $\mathrm{Y}$-shaped maze ${ }^{114}$ by Handley and Mithani in $1984^{115}$ and has since been widely used. The EPM has extensive pharmacological validation. Rats administered compounds that are anxiolytic in humans, such as benzodiazepines, increase the proportion of time spent in the open arm, while compounds that increase anxiety in humans, such as yohimbine, have the opposite effect ${ }^{112,113}$. Plasma corticosterone levels have also been shown to correlate positively with risk assessment and to increase with time spent in open arm ${ }^{113,116}$. In Paper II-III, basal, innate anxiety-like behavior was assessed using the EPM by scoring the percentage time spent in the open arms ${ }^{112,117}$.

\subsubsection{Controls for behavioral specificity}

\subsubsection{Novel object recognition}

To control whether the effects of Prdm2 knock-down are specific for fear memory (Paper II), we tested whether this manipulation affects other types of memory, using a novel object recognition (NOR) task. Objects were custom-built and made interactive (climbable) to increase exploration time and memory acquisition, as NOR is normally used to study short-term memory ${ }^{118}$. On day 1 , rats were habituated to the arena for $10 \mathrm{~min}$; on day 2 , rats were allowed $10 \mathrm{~min}$ to familiarize themselves with two copies 
of either object A or object B (counterbalanced); on day 3, rats were tested for novel object recognition by replacing one of the familiar objects with one that was novel. From this, a recognition index was calculated: time spent exploring novel object/(time spent exploring novel + familiar object).

\subsubsection{Locomotor activity}

Most behaviors, including alcohol self-administration and EPM, can be non-specifically affected by manipulations that also influence locomotor activity or motor performance. To control for non-specific effects of this type, in Paper I-II, locomotor activity was separately tested in sound attenuated chambers equipped with an infrared beam detection system for 30 min under ambient light levels. Data are presented as cumulative distance traveled in 5 min intervals.

\subsubsection{Foot shock sensitivity}

To rule out the possibility that Prdm2 knock-down affects fear expression by altering pain sensitivity, we measured foot shock sensitivity thresholds in Paper II. This was tested after completion of the 1week fear memory experiment. Rats were exposed to $0.5 \mathrm{~s}$ foot shocks in $0.1 \mathrm{~mA}$ increments and the retraction of 1, 2 and 4 paws was scored by a blinded observer.

\subsubsection{Saccharin self-administration}

To determine whether the effects of Syt1 knock-down (Paper I) are specific for alcohol or also extend to natural rewards, we performed operant saccharin self-administration under conditions similar to those under which we examined self-administration of alcohol. Saccharin was used to avoid the confound of caloric content. Rats were trained to self-administer $0.2 \%$ saccharin in 30 -minute sessions under FR1 (approx. 1 month) followed by FR2 (approx. 1 month). Once a stable self-administration baseline was reached, rats received viral vector injection into the PL. After two weeks, they were tested for saccharin self-administration under FR2.

\subsubsection{Quinine preference}

In Paper I, to control for taste reactivity, quinine preference was assessed using a two-bottle choice paradigm, where increasing concentrations of quinine were added to one bottle in their home cage. Quinine concentration was increased every 4 days and bottles were weighed and changed between sides every 2 days to avoid development of side preference.

\subsection{VIRAL VECTOR MANIPULATIONS}

Since its discovery in $1998^{119}$, RNA interference has evolved into a potent tool in molecular biology ${ }^{120}$. It utilizes the endogenous mechanism of microRNA (miRNA), in which short double stranded RNA:s interact with the RNA-induced silencing complex, to target and degrade mRNA that are complementary in sequence ${ }^{121}$. RNA interference can be performed experimentally either by introducing double stranded RNA directly (such as small interfering RNAs; siRNA), or by expressing it within the cell using viral DNA vector-mediated delivery (such as miRNA or short hairpin RNA; shRNA). While siRNAs offer the most straight-forward approach, they are limited by neuronal uptake-rates and the turnover of the genes of interest. They are therefore most useful for studying acute effects of a gene knock-down. In contrast, shRNA:s expressed using neurotropic viral vectors are more readily introduced into neurons. They require time to achieve stable expression but can have a lasting effect once this occurs. Viral vectors can also be used to co-express other constructs, such as fluorescent reporter proteins ${ }^{120,122}$.

By placing the vector cargo construct under a cell-specific promoter or under the control of a non-inert recombinase (which, in turn, can be placed under the control of a cell-specific promoter), it is further 
possible to manipulate gene expression in specific cell populations and neuronal projections ${ }^{123}$. A commonly used approach to achieve the latter objective is by using the Cre/lox system. Cre is a recombinase from the E. coli P1 phage that specifically recognizes short palindromic DNA sequences named loxP-sites ${ }^{124}$. When a gene is flanked by loxP-sites ("floxed"), depending on their orientation, the gene will either be excised (knocked-out) or inverted (turned on/off). More recently, mutant loxPsites have been designed and combined with wildtype loxP to create the more efficient double-floxed inverted open reading frame (DIO). Here, Cre will first recognize the mutant loxP-sites and mediate inversion, followed by excision of the wildtype loxP sites, which prevents further recombination ${ }^{122}$.

The most commonly used category of viral vectors in neuroscience are adeno-associated (AAVs). While their cargo capacity, i.e. the maximum size of the insert that can be expressed, is somewhat limited, they have a high transfection rate and good safety profile. Several serotypes exist, with varying transfection rates depending on cell-type and species ${ }^{125,126}$. These vectors have also been successfully engineered to achieve properties such as retrograde transport, allowing robust manipulations of projection specific populations (e.g., the AAV2-retro ${ }^{127}$ ).

Here, prelimbic knock-downs were carried out by bilateral stereotaxic infusions of an AAV9 containing a scrambled control, or shRNA targeting Syt1 (Paper I) or Prdm2 (Paper II)(figure 3A). Projection specific knockdowns were performed by bilateral infusions of an AAV9 containing a scrambled control, or DIO-miRNA targeting Syt1 or Prdm2 into the PL, and bilateral infusions of an AAV2-retro encoding Cre into the projection targets of the PL; NAc, BLA and the periaqueductal grey (PAG), separately (figure 3B).

In Paper II, a viral translating ribosomal affinity purification (VTRAP) experiment was also performed for analysis of downstream gene expression changes following Prdm2 knock-down. In this experiment, rats received bilateral infusions directly into the PL of a viral cocktail with 1:4 parts of an AAV9 containing an shRNA targeting Prdm2, or a scrambled control, and 3:4 parts of an AAV5 encoding a DIO- enhanced green fluorescent protein (EGFP)-tagged ribosomal subunit (EGFP-L10a). Rats also received bilateral infusions of the AAV2-retro encoding Cre into the BLA (figure $3 \mathrm{C}$ ). To measure neural activity in the BLA of behaving animals (Paper II), a fiber photometry experiment was conducted. Here, Prdm2 or scrambled control were infused into the PL (as above), and rats also received bilateral infusions of an AAV9 encoding the fluorescent calcium sensor GCaMP6s, followed by optic fiber implantation, into the BLA. The location and spread of the viral constructs were assessed and visualized ex vivo with confocal imaging, using fluorescent reporters incorporated into the viral vectors.
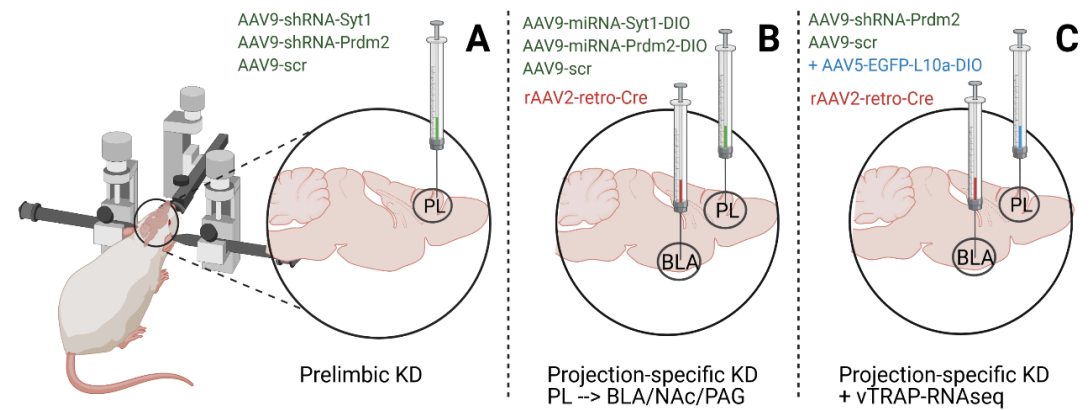

Figure 3. Schematic illustrating the viral vector manipulation strategies employed in the present work. Regional KD (A), projection-specific $K D(B)$ and projection-specific VTRAP (C). AAV: adeno-associated viruses; BLA: basolateral amygdala; DIO: double-floxed inverted open reading frame; EGFP: enhanced green fluorescent protein; KD: knock-down; NAc: nucleus accumbens; PAG: periaqueductal grey; PL: prelimbic cortex; RNAseq: RNA sequencing; scr: scrambled control; vTRAP: viral translating ribosomal affinity purification. 


\subsection{FIBER PHOTOMETRY}

Neuronal activity causes fast changes in intracellular free calcium. Using genetically encoded calcium indicators, this phenomenon can be utilized to monitor the activity of neuronal populations. One of the faster and most sensitive calcium sensors currently available is GCaMP6. It consists of a circularly permuted GFP, the calcium-binding protein calmodulin (CaM) and the CaM-interacting peptide M13. Three different isoforms exist, with varying kinetic properties (slow, medium, and fast; where slower kinetics result in higher sensitivity) ${ }^{128}$.

Immediately following neuronal activation, voltage-gated calcium channels in the plasma membrane open, and calcium enters the cell. When calcium binds CaM, the GCaMP complex undergoes a conformational change that results in light emission that can be recorded ${ }^{128}$. In vivo, this signal can be recorded while an animal is performing a behavior. The use of implantable miniature two-photon microscopes allows recoding of neural activity with a cellular resolution but limit the complexity of behaviors that can be studied. In contrast, fiber photometry lacks cellular resolution, but the small size and low weight of the implanted fibers are advantageous during behavioral experiments, and this methodology is also better established in rats. Despite its lower resolution, this method can provide important insights into the activity and dynamics within a defined circuit ${ }^{129}$.

In Paper II, we performed a pilot experiment using fiber photometry to record glutamatergic neural activity in the BLA during fear expression testing and in a neutral environment, following prelimbic knock-down of Prdm2. We used GCaMP6s under control of the CaMKII promoter to visualize the calcium signaling. This promoter is largely specific for glutamatergic neurons ${ }^{130}$. The slow isoform (GCaMP6s) was selected from pilot experiments (data not shown). Data are presented as $\Delta F / F$, the calcium-dependent signal with subtracted background fluorescence and normalized across animals, or AUC (area under the curve), which integrates the bulk signal over time.

\subsection{EX VIVO ELECTROPHYSIOLOGY}

Electrophysiological recordings allow a direct measure of neuronal activity and connectivity. Experiments on ex vivo brain sections can be performed either with extracellular or intracellular recordings of neuronal electrical activity. Extracellular recordings, such as local field potentials, generally result from synchronous activation of local neuronal populations or fibers and are useful to understand net changes in a region or circuit. In this method, stimulation electrodes are positioned near the recording electrodes, and evoked field potentials (population spikes) are used to generate e.g. a stimulus/response curve by stepwise increasing the stimulation strength ${ }^{131}$.

Intracellular recordings, such as whole-cell patch-clamp, are instead used to investigate mechanism at a single-cell resolution. Here, the recording electrode is placed on the cell membrane of a neuron. Suction is then applied to permeate the membrane and record the electrical signals that are produced by the passage of ions through specific channels expressed within the membrane ${ }^{132,133}$. With wholecell patch-clamp, it is also possible to record basal synaptic properties, such as frequency and amplitude of postsynaptic currents. These can indicate whether any differences following experimental manipulations are the result of changes in presynaptic release probability, or in the postsynaptic response ${ }^{134}$. To further investigate presynaptic release probability, a paired pulse stimulation protocol can be used with either extra- or intracellular recordings. Here, the stimulation occurs in rapid succession and the responses are used to generate a ratio (amplitude of the second response/first response) that is believed to reflect the probability of vesicular release in the 
presynaptic neuron ${ }^{135}$. Bath perfusions with agonists/antagonists can further be used to investigate mechanisms that underpin any differences.

In Paper I, local field potential recordings were performed on alcohol naïve rats in collaboration with the group of Louise Adermark at Gothenburg University, in order to assess the impact of Syt1 knockdown in the PL. Recordings were collected in the PL, NAc core, dorsomedial striatum, and the BLA. To monitor changes in GABAergic neurotransmission, changes in excitability were recorded during bath perfusion of the GABAA receptor antagonist bicuculline.

In Paper II, preliminary data were generated using whole-cell patch-clamp recordings to evaluate the effects of Prdm2 knock-down on glutamate release in synapses with principal BLA neurons. We analyzed the basal properties (frequency and amplitude) of spontaneous excitatory postsynaptic currents.

\subsection{GENE EXPRESSION ANALYSIS}

\subsubsection{Projection Specific VTRAP-RNA sequencing}

The most comprehensive method currently available for transcriptomic analysis is RNA sequencing $(\text { RNAseq })^{136}$. To analyze gene expression changes in ways that take in account cellular diversity and connectivity, this can be combined with other molecular methods. One of these is viral translating ribosomal affinity purification (VTRAP). In this method, a construct encoding an EGFP-tagged ribosomal subunit (L10a) is selectively expressed in neuronal populations of interest, using e.g. the Cre/lox system described previously. Due to redundancy (placing the construct under a constitutive promoter), the tagged subunit will be incorporated into the ribosomes of transfected cells. The EGFP-tagged ribosomes, and the translating RNA bound to them, can then be isolated with immunoprecipitation and subjected to gene expression analysis using RNAseq. The main advantage of using TRAP is that the mRNA associated with the ribosomes is in the process of translation. Translation occurs after many of the gene expression regulatory events have already taken place, and translating mRNA will therefore more closely correlate with the protein levels. Another advantage is that this approach allows for celltype specific RNA profiling, without the need to first dissociate the cells into suspension, which can introduce noise ${ }^{137}$.

To identify the molecular mechanisms downstream of Prdm2 knock-down in Paper II, specifically in neurons projecting from the PL to the BLA, we performed VTRAP-RNAseq. In Prdm2 knock-down and scrambled controls, EGFP-L10a was expressed selectively in this projection. After one month, the PL was dissected freshly, and RNA was extracted with immunoprecipitation (TRAP) and subsequently purified. Library preparation and RNAseq was performed at the National Genomics Infrastructure (Sweden), and analysis of the data was carried out in collaboration with Dr. Cantù's lab at Linköping University.

\subsubsection{NanoString}

NanoString is a fast, simple, and highly quantitative medium-throughput technology for analysis of gene expression changes ${ }^{138,139}$. It does not require cDNA conversion, amplification, or library preparation, and allows the simultaneous quantification of up to 800 genes, with a high sensitivity and linearity over multiple orders of magnitude. In this technique, a premade code set containing genespecific fluorescently barcoded reporter probes and biotin-labeled capture probes are hybridized directly to purified RNA. The tripartite complex is then immobilized and electrostretched on a streptavidin cartridge, whereafter the fluorescent barcodes are counted ${ }^{140}$. 
In Paper III, gene expression analysis was performed using our custom code set NanoString panel containing 383 transcripts ${ }^{69}$. These have been selected and added over time, from the literature and previous experiments, based on their involvement in psychiatric disorders and drug-relevant behaviors. In brief, the AMG was dissected freshly, and flash frozen for later RNA extraction. RNA was analyzed at KIgene (Karolinska Institute, Solna, Sweden) and data were analyzed using nSolver. Targets identified with NanoString were independently confirmed with qPCR. qPCR was performed using TaqMan reagents and inventoried assay probes, and were analyzed with the $2^{-\Delta \Delta c t}$ method $^{141}$.

\subsubsection{In situ gene expression analysis}

To assess the efficiency of the viral vector knock-downs in Paper I-II, while maintaining anatomical resolution, we used the fluorescent in situ hybridization method RNAScope ${ }^{\circledR}$. In this method, target probes complementary to the transcript of interest hybridize contiguously forming a target region for a preamplifier. The preamplifier then contains binding sites for 20 amplifier probes, each of which, in turn, contains 20 binding sites for the fluorescent label probes. This allows transcripts to be amplified to a point where they can be individually detected and counted in a highly quantitative fashion. Probes can also be multiplexed to investigate e.g. cell-specific transcriptional changes ${ }^{142}$.

In brief, brains were removed, and flash frozen after completion of the experiment. Sections were collected at the PL level and in situ hybridization was performed through a series of incubations with amplifier probes. During the last step, sections were incubated with the fluorescent label probe to visualize the transcript. Microphotographs for quantification were obtained using a confocal microscope, and mRNA levels were assessed as total pixels of the fluorescent signal (fluorescent "dots"), normalized per cell ${ }^{143}$.

\subsection{PLASMA CORTICOSTERONE ANALYSIS}

Corticosterone is released from the adrenal glands following activation of the hypothalamic-pituitaryadrenal axis, and correlates with the level of stress that an animal is experiencing ${ }^{144}$. In Paper III, we collected blood samples from tail veins of rats at baseline and $10 \mathrm{~min}$ after last SDS session, and in Paper II, we collected blood samples at baseline, $10 \mathrm{~min}$ after conditioning and $10 \mathrm{~min}$ after the expression test in one of the batches.

\subsection{EXPERIMENTAL OVERVIEW AND TIMELINES}

\subsubsection{Paper I: Downregulation of Synaptotagmin 1 in the prelimbic cortex drives alcohol associated behaviors in rats}

In Paper I, 6 experiments were performed to investigate the role of Syt 1 in alcohol associated behaviors (figure 4). After operant alcohol self-administration training and viral vector surgeries, rats were tested for several behaviors aimed at investigating alcohol consumption (alcohol self-administration), motivation to consume alcohol (progressive ratio) and compulsive-like behavior (quinine adulteration). Multiple control experiments were also conducted to investigate the specificity of Syt1 knock-down for alcohol-related behaviors. In separate experiments, performed in collaboration with the Adermark group, ex vivo electrophysiology following Syt1 knock-down was recorded in alcohol naïve rats. 


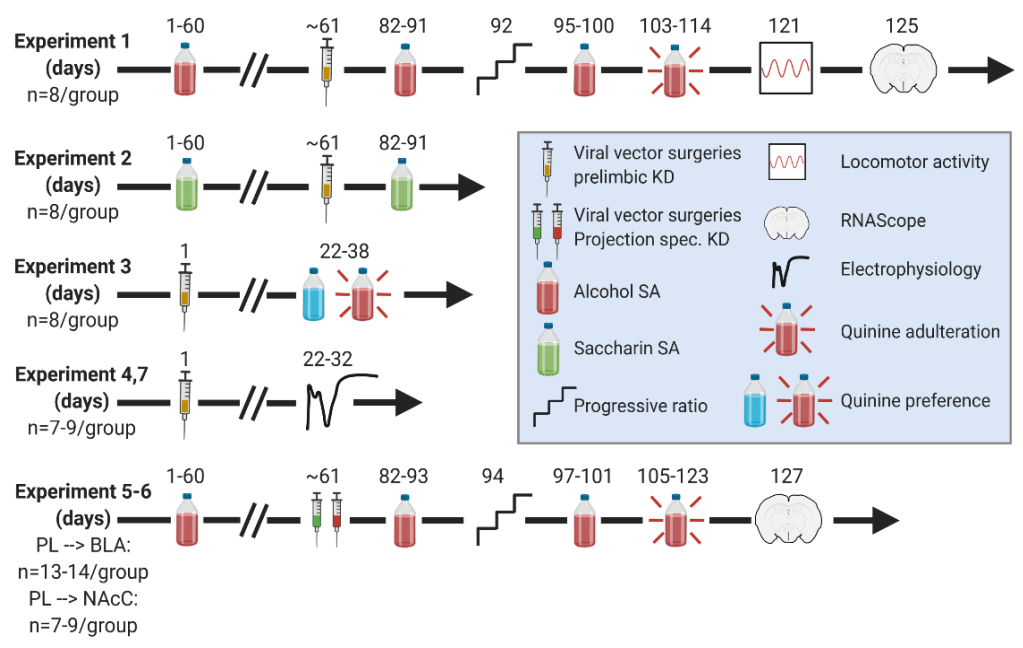

Figure 4. Experimental design and timelines. 6 experiments were performed in this study and are detailed in the timelines above. BLA: basolateral amygdala; NACC: nucleus accumbens core; KD: knock-down; SA: self-administration.

\subsubsection{Paper II: Prdm2 modulates fear memory consolidation through neurons projecting from prelimbic cortex to the basolateral amygdala}

Eight experiments were carried out in Paper II, where we investigated the role of Prdm2 in cued fear conditioning (figure 5). In experiments 1-5, Prdm2 was knocked down in the PL and several components of fear memories were investigated, along with controls for behavioral specificity. In experiment 6 and 7, Prdm2 was knocked down specifically in neurons projecting from the PL to the BLA and PAG respectively, and rats were subjected to the cued fear conditioning paradigm. In experiment 8, we used vTRAP to analyze gene expression following Prdm2 knock-down specifically in the neurons projecting from the PL to the BLA.

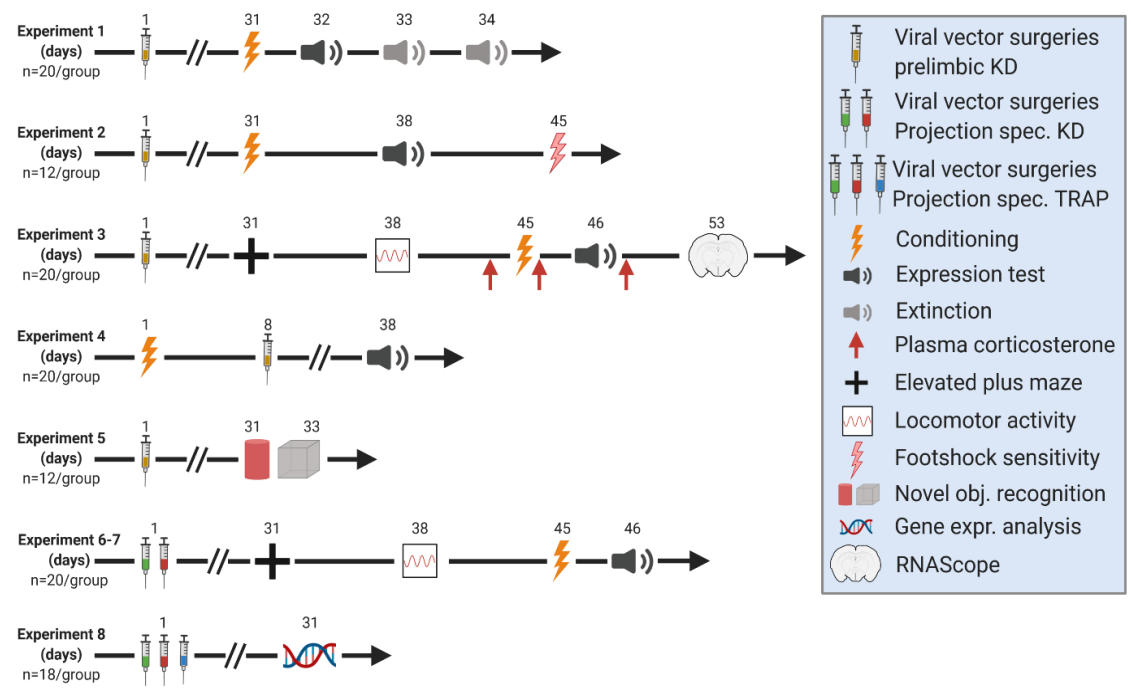

Figure 5. Experimental design and timelines. 8 experiments have been completed in this study investigating the role of Prdm2 in cued conditioned fear. KD: knock-down; TRAP: translating ribosome affinity purification. 
Additionally, preliminary data were generated from a) a fiber photometry experiment where the effects of PL Prdm2 knock-down on the neural activity in the BLA were investigated and b) ex vivo electrophysiological recordings from neurons in the BLA following PL Prdm2 knock-down.

\subsubsection{Paper III: Stress-induced escalation of alcohol self-administration, anxiety-like behavior, and} elevated amygdala Avp expression in a susceptible subpopulation of rats

Five batches of rats underwent the SDS paradigm $(\mathrm{N}=216)$. Following habituation and handling, rats were trained to self-administer $20 \%$ alcohol for approximately 2-3 months. Rats were then subjected to 10 days of SDS, for $10 \mathrm{~min} /$ day. All rats were kept single-housed for the remaining part of the experiment. Blood samples (batches 1-4) and body weights (batches 1-5) were collected before the start of- and after the last SDS session. After one week of rest, we assessed anxiety-like behavior on the EPM. After another week of rest, rats were returned to alcohol self-administration for one week. The AMG from rats in batches 2-5 were collected for gene expression analysis. An overview of this timeline is illustrated in figure 6 .

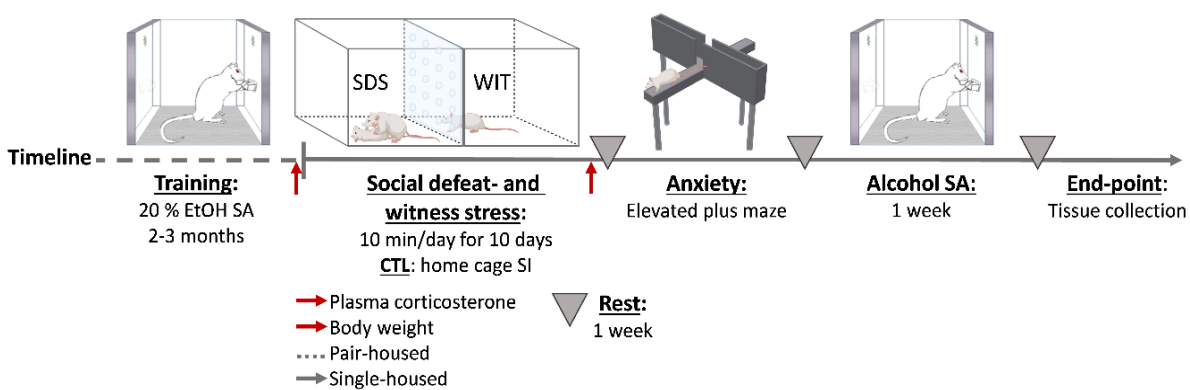

Figure 6. Experimental timeline of the social defeat-and witness stress paradigm used in study III. After baseline selfadministration (SA), rats underwent social defeat- or witness stress. One week after the last stress session, anxiety-like behavior was assessed using the elevated Plus Maze (EPM). Alcohol self-administration was tested 1 week after the EPM. One week after the end of the behavioral tests, the amygdala was collected to explore long-term gene expression changes. CTL: control; EtOH: ethanol; SDS: social defeat stress; WIT: Witness. 


\section{RESULTS AND DISCUSSION}

\subsection{PAPER I: DOWNREGULATION OF SYNAPTOTAGMIN 1 IN THE PRELIMBIC CORTEX DRIVES ALCOHOL ASSOCIATED BEHAVIORS IN RATS}

Alcohol addiction is characterized by persistent neuroadaptations in brain structures that control motivation, decision making and emotion, including the MPFC, AMG and NAc. We previously found that a history of alcohol dependence was associated with long-term changes in the expression of genes that regulate neurotransmitter release in the $\mathrm{mPFC}^{67}$. Specifically, we observed a DNA methylationdependent downregulation of Synaptotagmin 1 (Syt1), a gene product that has an important role in neuronal function and neurotransmitter release ${ }^{145}$. We therefore hypothesized that Syt1 downregulation may be a mechanism that promotes alcohol addiction-like behaviors and aimed to functionally examine this using viral vector-based manipulations in rats.

\subsubsection{Prelimbic Syt1 knock-down promotes alcohol-addiction like behaviors}

After operant alcohol self-administration training and baseline, Syt1 was selectively knocked down in the PL using an shRNA. After approximately three weeks, rats were tested for a battery of alcoholrelated behaviors. We found that Syt1 knock-down significantly increased alcohol self-administration and motivation to consume alcohol, compared both to baseline, and to a scrambled control group. The increased self-administration lasted for at least 9 days, suggesting a persistent effect of the knockdown on this behavior. Syt1 knock-down rats also demonstrated a compulsive-like behavior, measured as resistance to quinine adulteration. Overall, the behavioral consequences of Syt1 knock-down mimic those observed in rats with a history of alcohol dependence ${ }^{146}$. Our findings functionally link prelimbic downregulation of Syt1 to alcohol-related behaviors, such as continued drug taking despite adverse consequences and a high motivation to seek/take alcohol.

\subsubsection{Behavioral effects of Syt1 knock-down are specific for alcohol}

A series of control experiments was performed to determine the specificity of Syt1 knock-down effects on alcohol-related behaviors. The controls included saccharin self-administration, locomotor activity and quinine preference. We did not observe differences in any of these behaviors between Syt 1 knockdown and scrambled controls. This shows that the effects of Syt1 knock-down on alcohol-related behaviors are not due to nonspecific effects such as behavioral disinhibition, taste reactivity or generally increased valuation of appetitive rewards.

\subsubsection{Syt1 knock-down reduces neural excitability in the PL}

Using ex vivo local field potential recordings, we found a decreased neuronal excitability in the PL following Syt1 knock-down. Recordings demonstrated a marked reduction in evoked field potentials and an increased paired-pulse ratio. Field potentials in the PL are mainly glutamatergic and mediated through AMPA receptor activity ${ }^{147}$. Our findings thus suggest that glutamatergic neurotransmission is reduced in the PL following Syt1 knock-down, and, by extension, is reduced following alcohol dependence. Consistently, the MPFC, including the PL, is commonly found dysregulated in patients with addictive disorders, and specifically hypoactive in the absence of drug-related cues ${ }^{20}$. A postmortem study in the PFC of alcohol-dependent patients with liver cirrhosis further found a large number of genes involved in synaptic neurotransmission to be downregulated, suggesting a net reduction of neurotransmission in the PFC of these patients ${ }^{148}$. The parallel increase in paired-pulse ratio suggests that suppression of evoked potentials following Syt1 knock-down occurs through a reduced release probability of glutamate. This is in line with the postulated role of SYT1 as the main calcium sensor for fast presynaptic vesicle exocytosis ${ }^{145}$. 


\subsubsection{Syt1 knock-down in neurons projecting from the PL to the BLA promotes compulsive-like behavior}

To identify the circuits through which Syt1 regulates alcohol-related behaviors, we selectively inhibited its expression in neurons projecting from the PL to the BLA or NAc, respectively. We focused on these projections, as they have been implicated in regulation of alcohol drinking ${ }^{23,24}$.

Our results showed that Syt1 knock-down in the PL-BLA projection increased compulsive-like alcohol taking, mimicking what had previously been observed following a history of alcohol dependence ${ }^{146}$ and also after a full prelimbic knock-down. We did not observe any effects on alcohol self-administration or in the motivation for alcohol taking in rats with selective Syt1 knock-down in the PL-BLA projection compared to scrambled controls. Rats with selective Syt1 knock-down in the PL-NAc projection did not differ from scrambled controls in any of the behaviors assessed. To our knowledge, the present study is the first to demonstrate a role of the BLA in compulsive alcohol taking.

\subsubsection{Syt1 knock-down increases neuronal excitability in the BLA}

In support of our behavioral findings, the BLA but not the NAC showed differences in neuronal activity following PL Syt1 knock-down. Evoked potentials in the BLA were significantly increased; in contrast to what we observed in the PL (see above), no effect was observed in the paired-pulse ratio. When the GABA-A receptor antagonist bicuculine was introduced, disinhibition was significantly less pronounced in the BLA of Syt1 knock-down rats, compared to controls. Bicuculine further normalized stimulus/response curves, which indicates that a reduced GABAergic neurotransmission underlies the observed increase in BLA excitability after Syt1 knock-down. Increased excitability in the BLA following PL Syt1 knock-down is broadly consistent with reports in the literature. Specifically, changes in the regulation of BLA excitability have been associated with behavioral consequences that include anxiety, relapse to drug use and dysregulated emotional reactivity, behaviors commonly observed in patients with addictive disorders ${ }^{149-151}$. Preclinically, hyperexcitability of the BLA has been observed following chronic intermittent alcohol exposure ${ }^{152}$.

A schematic summarizing the findings in Paper I is given in figure 7.

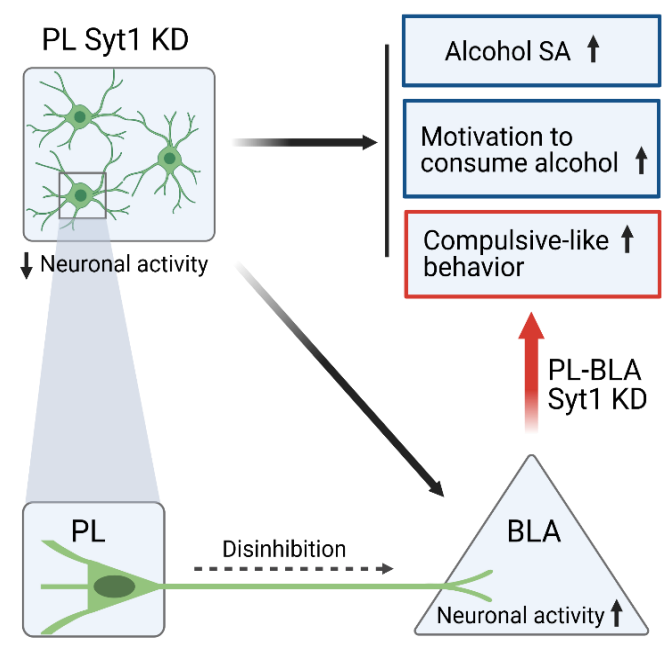

Figure 7. Knock-down (KD) of Syt1 in the prelimbic cortex (PL) of rats promotes alcohol addiction-like behaviors. Projectionspecific KD in PL-BLA neurons are sufficient to increase compulsive-like behavior. PL Syt1 KD also decreases the neuronal activity in the $P L$ and increases neural activity in the in BLA, possibly through disinhibition of GABA. 


\subsubsection{Paper I: conclusion}

In Paper I, we demonstrate a mechanistic role of prelimbic Syt1 in several behaviors that are characteristic of alcohol addiction. We identified the PL-BLA projection as a brain circuit through which SYT1 regulates compulsive alcohol taking, an important feature of clinical alcohol addiction ${ }^{153}$. Collectively, our data suggest that dysregulation of the synaptic calcium sensor SYT1 in glutamatergic projections from the PL to the BLA is a mechanism through which a history of alcohol dependence causes long-term neuroadaptation that promotes addiction-like behaviors.

\subsection{PAPER II: PRDM2 MODULATES FEAR MEMORY CONSOLIDATION THROUGH PROJECTIONS FROM THE PRELIMBIC CORTEX TO THE BASOLATERAL AMYGDALA}

PRDM2 is an epigenetic enzyme that methylates lysine 9 on histone 3 , which is generally considered a repressive mark for gene transcription ${ }^{70,71}$. We have previously shown that downregulation of Prdm2 in the PL of rats promotes stress-induced relapse to alcohol seeking, as demonstrated by an increased response to foot shock stress ${ }^{69}$. Given the high prevalence and overlapping neuronal substrates of comorbid alcohol use- and anxiety disorders ${ }^{154-157}$, we hypothesized that Prdm2 deficiency in the PL may not only increase stress-induced relapse, but also potentiate pathological fear expression.

\subsubsection{Prdm2 knock-down in the PL causes a long-lasting increase in fear expression by modulating memory consolidation}

Prdm2 was selectively knocked down in the PL of rats using an shRNA. After approximately one month of recovery, rats were subjected to a cued fear conditioning paradigm. Prdm2 knock-down rats showed a significantly higher fear expression compared to scrambled controls when tested $24 \mathrm{~h}$ after acquisition of fear learning. In a separate experiment, we tested fear expression one week after the acquisition, and found that the effect of Prdm2 knock-down to increase fear expression persisted. Prmd 2 knock-down did not affect acquisition or extinction of the fear memory, as percentage time spent freezing and the rate of extinction (group $x$ time interaction), respectively, was similar to that of controls. An enhanced fear expression was, however, seen after three days of extinction. This is in line with several other studies, where the PL has been shown to be involved in the expression but not the extinction of fear memories ${ }^{158-160}$. Collectively, these findings indicate that expression of conditioned fear is persistently increased in rats with Prdm2 knock-down, despite normal extinction rates.

The lack of effect of Prdm2 knock-down on acquisition of conditioned fear indicated that PRDM2 does not act directly on the associative learning processes that links the US (foot shock) with the CS (cue tone $)^{160,161}$. This left the possibilities that Prdm2 knock-down acts either on consolidation or memory retrieval processes to increase the fear expression. To address this question, we knocked down Prdm2 one week after fear conditioning. Given the time necessary for the shRNA to stably reduce Prdm2 expression, most of the consolidation processes had been formed in the PL by this time ${ }^{77}$. Under these conditions, we did not observe differences in fear expression between Prdm2 knock-down rats compared to scrambled controls. In summary, these data suggest that Prdm2 knock-down increases fear expression by modulating memory consolidation rather than memory recall.

\subsubsection{Effects of Prdm2 knock-down are specific for fear memories}

We performed a series of control experiments to verify that the observed effects were specific for the expression of fear. To investigate if the effects of Prdm2 knock-down also extend to other types of memories, rats were tested for novel object recognition. We did not observe any differences in novel object recognition between Prdm2 knock-down and scrambled controls. Both groups had a recognition index $>0.5$, indicating that they successfully recognized the novel object ${ }^{118}$. While this test alone does 
not rule out the possibility that Prdm2 affects other types of memories, it demonstrates that it does not induce a general effect on memory processes.

Furthermore, when basal, innate anxiety was tested on the EPM, we observed no differences between Prdm2 knock-down and scrambled controls, although a weak trend for a decreased percentage time spent in the open arm was seen in the Prdm2 knock-down rats. In contrast to the auditory fear conditioning model, the EPM relies on innate, unconditioned, avoidance of potentially dangerous environments (open spaces) ${ }^{113}$. In Paper II, the lack of an effect on the EPM indicates that the increased conditioned fear expression does not result from an elevated basal anxiety level, but rather from processing of the fear memory. This is corroborated by the lack of effect on acquisition and by the experiment where Prdm2 knock-down after acquisition of conditioned fear did not affect its expression.

A phenomenon of high clinical relevance in anxiety disorders is generalization. This refers to impaired discrimination between fear associated and neutral cues, and results in maladaptive fear responses to stimuli that do not signal a threat ${ }^{78}$. In Paper II, we assessed this by measuring the time spent freezing during the first minute of the test session, i.e. fear expression in a similar but novel context, $24 \mathrm{~h}$ after conditioning. We observed no differences between groups, indicating that Prdm2 knock-down does not impair contextual discrimination. This does not, however, exclude the possibility that discrimination between discrete cues might be affected.

Finally, we did not observe any differences in locomotion, foot shock sensitivity, or plasma corticosterone levels after the Prdm2 knock-down. These observations indicate that Prdm2 knockdown does not alter fear memory expression indirectly by altering locomotor activity, pain perception, or HPA-axis activity, respectively.

\subsubsection{Prdm2 knock-down in projections from the PL to the BLA are sufficient to promote conditioned fear}

Several studies have demonstrated the importance of PL and BLA in regulating conditioned fear ${ }^{162,163}$, and bidirectional connectivity between these regions has been shown to play a key role in the expression of conditioned fear ${ }^{164,165}$. Here, we further demonstrate that Prdm2 knock-down specifically in the PL-BLA projections enhanced fear expression, with an effect size comparable to that of a global PL knock-down. In contrast, in a separate experiment, we observed no effect of a Pdrm2 knock-down restricted to neurons that project from the PL to the dorsolateral PAG, another region that is important for regulation of fear responses such as freezing behavior ${ }^{166-168}$. Together, this suggests that prelimbic Prdm2 knock-down increases fear expression specifically by modulating the activity of neurons that project from the PL to the BLA.

\subsubsection{Prdm2 knock-down in the PL results in increased neuronal activity in the BLA}

To investigate the impact that PL Prdm2 knock-down has on the BLA, we used fiber photometry to visualize neuronal activity in the BLA of rats, at baseline and during fear expression testing. Results from a pilot experiment show that Prdm2 knock-down in the PL results in increased neuronal activity both at baseline (measured in a neutral context prior to any training; figure $\mathbf{8 A}$ ), and during fear expression testing (main effect of group; figure 8B).

Slice electrophysiology was carried out to examine possible synaptic mechanisms behind the increased neuronal activity identified in the calcium imaging experiments. Preliminary data from patch-clamp electrophysiological recordings indicate an increased presynaptic release probability in the BLA of Prdm2 knock-down rats compared to control. This was demonstrated by an increased frequency, but not amplitude, of spontaneous excitatory postsynaptic currents in glutamatergic principal neurons in 
Prdmd 2 knock-down rats (figure $8 \mathrm{C}$ and $\mathbf{D}$, respectively) ${ }^{134}$. This is in line with other studies showing that activation of the BLA causes an increased fear expression ${ }^{161}$. Substantial evidence supports the notion that fear expression critically relies on activation of the PL-BLA circuit. Cued conditioned fear has been shown to strengthen the PL excitatory synapses in the BLA ${ }^{162}$, and optogenetic silencing of the PL terminals in the BLA decreases both fear expression and active avoidance ${ }^{77,165}$. Therefore, it is possible that decreased Prdm2 expression participates in excessive activation of this circuit.
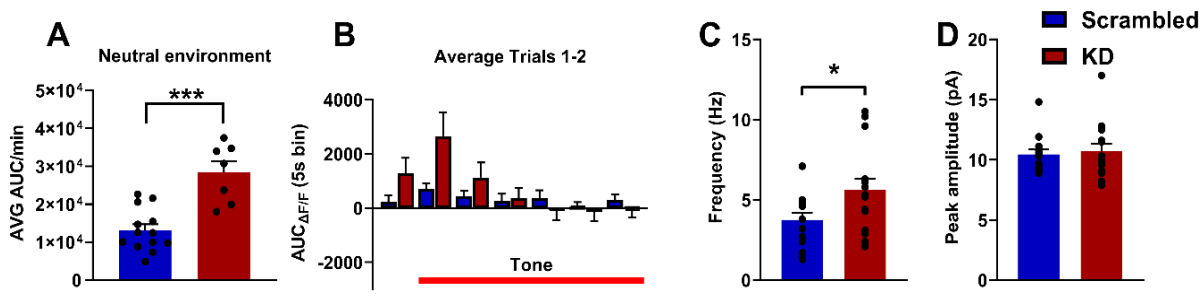

Figure 8. Prelimbic (PL) Prdm2 knock-down (KD) increases neural activity in the basolateral amygdala (BLA). Preliminary fiber photometry data demonstrate an increased activity of the BLA in Prdm2 KD animals compared to scrambled control. This activity is seen both in a neutral context (A) and at tone onset during fear expression testing (B). Whole-cell patch-clamp recordings demonstrate an increase in the spontaneous firing frequency of principal glutamatergic neurons in the BLA (C), but not amplitude (D), indicative of an increased presynaptic probability of release. ${ }^{*} p<0.05 ;{ }^{* * *} p<0.001$.

\subsubsection{Knock-down of Prdm2 modulates the expression of genes involved in synaptogenesis}

Thus, our results establish that Prdm2 modulates consolidation of conditioned fear through actions in neurons that project from the PL to the BLA. Given the role of $P r d m 2$ as an epigenetic regulator of gene expression, its effects are likely to be mediated through changes to the transcriptomic repertoire within these neurons. To investigate these downstream transcriptomic effects of Prdm2, we used projection-specific VTRAP-RNA sequencing.

$\operatorname{Prdm} 2$ knock-down resulted in broad and robust changes to the transcriptome within the population of PL neurons that project to the BLA. Of particular relevance for memory processes, we found that Prdm2 knock-down regulates the expression of genes associated with synaptogenesis. The top gene networks that were found using Ingenuity pathway analysis ${ }^{\circledR}$ (IPA) include genes that belong e.g. to the Ephrin family, neuroglinin and neurexin families, and SNARE associated genes (such as synaptotagmins). These gene families are known to contribute to memory formation ${ }^{169}$, synaptic function ${ }^{170}$, and neurotransmission ${ }^{171}$, respectively.

In summary, these findings suggest that decreased Prdm2 expression increases cued conditioned fear expression by strengthening the memory consolidation, and does so by strengthening synaptic connections within the PL-BLA circuit. Memory consolidation is formed through the regulation of gene transcription and protein synthesis, where genes that regulate synaptic function are believed to be particularly relevant ${ }^{172-174}$. PRDM2, which regulates gene expression through histone methylation ${ }^{70}$, may be a key mechanism in the regulation of the molecular engrams involved in fear memory consolidation. A schematic summarizing the complete findings in Paper II is given in figure $\mathbf{9}$. 


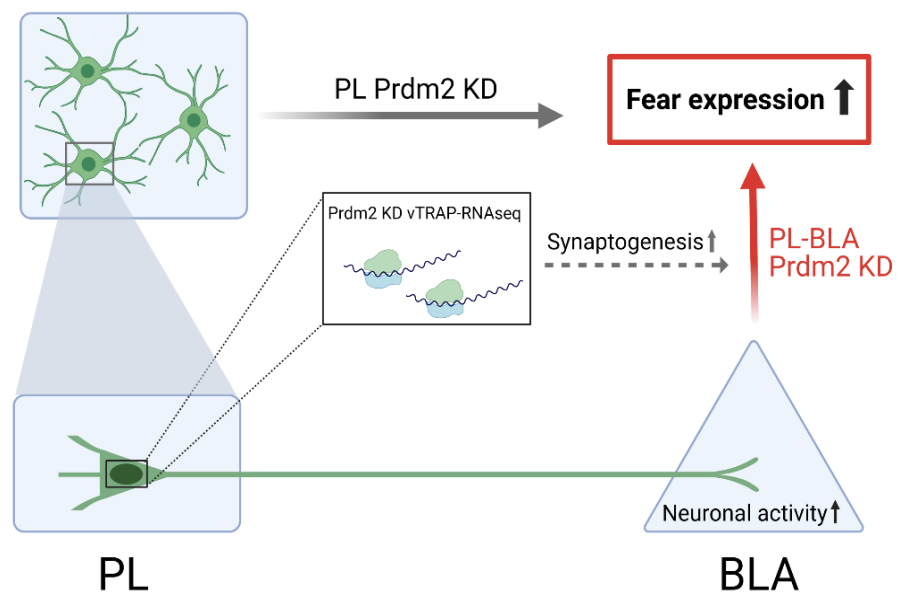

Figure 9. Knock-down (KD) of Prdm2 in the prelimbic cortex (PL) increases fear expression. Selective KD in neurons projecting from the PL to the BLA is sufficient to replicate this effect. Viral translating ribosomal affinity purification (VTRAP) RNA sequencing (RNAseq) performed specifically in the PL-BLA neurons identifies upregulated expression of a gene network associated with synaptogenesis. Increased synaptogenesis in PL-BLA neurons can account for strengthened fear memory consolidation, which underlies the observed increase in fear expression following Prdm2 KD.

\subsubsection{Paper II: conclusion}

In Paper II, we show that downregulation of the epigenetic enzyme PRDM2 in neurons projecting from the PL to BLA was sufficient to persistently increase the expression of cued conditioned fear in rats. Knock-down of Prdm2 leads to an upregulated expression of synaptogenesis-associated genes, and an increased activation of the BLA. Our data further suggest that PRDM2 regulates fear expression by modulating fear memory consolidation, and specifically strengthening this process by promoting synaptogenesis in the PL-BLA circuit. Prdm2 downregulation may thus be an important mechanism in the development of excessive and enduring fear, a central feature of anxiety disorders.

\subsection{PAPER III: STRESS-INDUCED ESCALATION OF ALCOHOL SELF-ADMINISTRATION, ANXIETY-LIKE BEHAVIOR, AND ELEVATED AMYGDALA AVP EXPRESSION IN A SUSCEPTIBLE SUBPOPULATION OF RATS}

Stress promotes the development of both anxiety disorders and alcohol addiction. Notably, stressrelated psychopathology may develop not only from firsthand experience of traumatic events, but also from witnessing them ${ }^{34,37-39}$. Here, we used a model of social defeat- and witness stress in rats to investigate shared mechanisms of stress-induced anxiety-like behavior and escalated alcohol selfadministration.

\subsubsection{Social defeat- and witness stress induce persistent comorbid anxiety-like behavior and escalation of alcohol self-administration in a susceptible subpopulation of rats}

Using a thresholding approach to define escalated alcohol intake and high anxiety-like behavior, we found that both social defeat- and witness stress significantly increased the proportion of rats showing both these characteristics (i.e. were "comorbid"), compared to controls that had not been exposed to $\operatorname{SDS}(19,14$ and $5 \%$, respectively). A higher proportion of rats showed a stress-induced anxiety-like behavior than stress-induced escalation of alcohol intake, and approximately $20 \%$ of social defeatand witness stressed rats showed resilience to the stress. 
We used factor analysis as an unbiased method to identify underlying patterns in the data. This analysis confirmed that escalation of alcohol intake and increased anxiety-like behavior load on the same factor, which explained the highest proportion of variance (35\%). We then plotted the factor scores back onto our threshold-defined groups and confirmed that the variance is driven by the comorbid subpopulations. It should be noted that the low proportion of control rats with increased anxiety-like behavior and escalation of alcohol self-administration may still overestimate the true baseline frequency of this behavioral profile. This is because the controls had to be single-housed, which in itself is a mild stressor ${ }^{102,175}$. Overall, the individual variation in susceptibility and resilience to stress in these experiments resembles the pattern that is observed in humans, where only a minority of those exposed to the stress develop a psychiatric disorder ${ }^{26}$. This supports a translational validity of the model.

Our findings that SDS induces anxiety-like behavior in a subpopulation of rats are consistent with what others have found. For instance, Bosh-Bouju et al. reported that about half of mice exposed to SDS showed increased anxiety-like behavior ${ }^{52}$. With regard to effects of SDS on alcohol self-administration, findings are less consistent. At a group-level, increased ${ }^{176}$, unchanged ${ }^{177}$ or decreased ${ }^{178}$ alcohol intake has been reported following SDS. These discrepancies may be explained by the fact that alcohol intake has been assessed at different timepoints following SDS. To our knowledge, no study has investigated individual differences in alcohol intake following SDS. Our work extends prior work by identifying a susceptible subpopulation, and showing that both social defeat- and witness stress lead to comorbid increases in anxiety-like behavior and escalation of alcohol intake. These characteristics persist for at least two and three weeks, respectively, after the last SDS session.

Body weight measurements showed a growth retardation in both comorbid and resilient SDS rats, but not in witness or control groups. This indicates that, when experienced firsthand, SDS is a significant physical stressor ${ }^{102}$; however, the intensity of this stressor does not predict subsequent anxiety or alcohol intake in this model. This was corroborated by behavioral scoring of the SDS sessions, where no differences were observed between resilient and comorbid groups in e.g. the number of attacks by the aggressor. Comorbid SDS rats did show significantly elevated corticosterone levels compared to controls (not resilient SDS), but with large individual variation.

\subsubsection{Association between AMG gene expression, stress type, and behavioral characteristics}

Having defined susceptible and resilient subpopulations, our next objective was to investigate the molecular mechanisms associated with these characteristics, and to examine whether these mechanisms are distinct or shared between firsthand and witness SDS. We focused our analysis on the AMG, as we and others have previously found this structure to be critically involved in the association between alcohol- and anxiety-related behaviors ${ }^{18,83}$. One week after the last alcohol selfadministration session, the AMG was collected, and gene expression profiles were generated using a NanoString panel containing 383 genes.

We found 15 genes that were significantly different in comorbid SDS rats and 17 genes in the resilient $\mathrm{SDS}$, compared to control. Among these, two genes were common to the groups. A similar pattern was observed in the comorbid (19 significant genes) and resilient (12 significant genes) witness groups, with three genes in common. This suggests that the majority of genes identified are not triggered by the stress itself but may be relevant for the observed behaviors; anxiety-like behavior and escalation of alcohol intake. Comparing resilient SDS and witness groups, one gene was commonly downregulated whereas comorbid SDS and witness groups had four similarly regulated genes. Finding that social defeat- and witness stress have largely distinct gene expression profiles indicates that both stressors can lead to similar behavior in part through different molecular mechanisms. Focusing on the 
overlapping genes may, however, help identify the mechanisms that mediate the stress-induced comorbid AUD and anxiety ${ }^{179}$.

\subsubsection{Amygdala Avp correlates with the magnitude of comorbidity}

Of the four overlapping genes found between comorbid SDS and witness rats, only Avp (vasopressin) was specific to these groups and not affected in either of the resilient populations. The related Oxt (oxytocin) gene showed a similar trend, and was therefore included in downstream analysis. Both genes were strongly upregulated, with a fold-change $>20$ in both comorbid groups, which was confirmed with qPCR. Using a comorbidity index $(\mathrm{Cl})$ generated to account for both anxiety and alcohol intake, we found a robust correlation between both genes and the $\mathrm{Cl}$ in SDS rats (Avp: $\mathrm{r}^{2}=0.4, p=0.016$; Oxt: $r^{2}=0.39, p=0.017$ ), with a similar trend in witness rats (Avp: $r^{2}=0.2, p=0.1 ; O x t: r^{2}=0.19, p=0.12$ ). No correlation was seen between either of the genes and $\mathrm{Cl}$ in controls, suggesting a role of these neuropeptides in stress-induced comorbid escalation of alcohol intake and anxiety-like behavior.

In line with these findings, several studies have identified a role of Avp in stress-regulation and mood disorders ${ }^{180,181}$. Notably, Avp has been found to positively correlate with alcohol intake in mice exposed to $\mathrm{SDS}^{182}$, and microinfusion of AVP into the central AMG has been shown sufficient to induce anxietylike behavior ${ }^{183}$. Polymorphisms in the Avp promoter, leading to an increased expression of the gene, have also been associated with increased anxiety-like behavior in Wistar rats ${ }^{184}$. In humans, several studies report increased stress response and elevated amygdala activity following intranasal administration of AVP ${ }^{185-187}$. Polymorphism in the AVP receptor 1 promoter has also been associated with e.g. social behaviors following childhood adversities ${ }^{188}$, although this type of candidate gene association study will require replication. Together, this suggests that Avp may be a vulnerability factor underlying individual differences in susceptibility to stress. Additional experiments are needed to determine whether higher Avp expression observed in our comorbid rats reflect a pre-existing condition or whether it is induced from an interaction with the environment.

Unexpectedly, Oxt mRNA levels were also increased in the AMG of comorbid animals. Contrary to our findings, oxytocin has been shown to exert anxiolytic properties in humans and reduce anxiety-like behavior in rodents ${ }^{189}$. Oxytocin has also been proposed as a medication to enhance the effects of psychotherapy in patients with PTSD ${ }^{190}$. Release of oxytocin in the AMG comes mainly from neurons that originate in the hypothalamus and, to our knowledge, the role of Oxt expression in AMG neurons has not been explored. One possibility, given the chromosomal proximity of $A v p$ and Oxt, is that the increased expression of $O x t$ observed in our data may be driven by a common regulatory element. Rather than having a functional impact on anxiety-like behavior and alcohol intake, it would therefore be a bystander effect of Avp upregulation.

\subsubsection{Preexposure to alcohol}

In our SDS paradigm, rats are trained on alcohol self-administration prior to the stress, as this is necessary to measure escalation of self-administration at an individual level. To investigate if the amount of baseline alcohol self-administration predicts stress reactivity in our animals, we ran correlational analyses between baseline alcohol intake, Avp expression, and behaviors; no such correlations were observed. This does not completely rule out the possibility that prior exposure to alcohol contributes to behavioral outcomes or Avp expression, but renders this unlikely. Further, our model also mimics the human situation in which most adults establish low - moderate levels of alcohol use, but only a minority of these users progresses into AUD ${ }^{191}$.

A schematic summarizing the findings in Paper III is given in figure 10. 
Social defeat- and witness stress

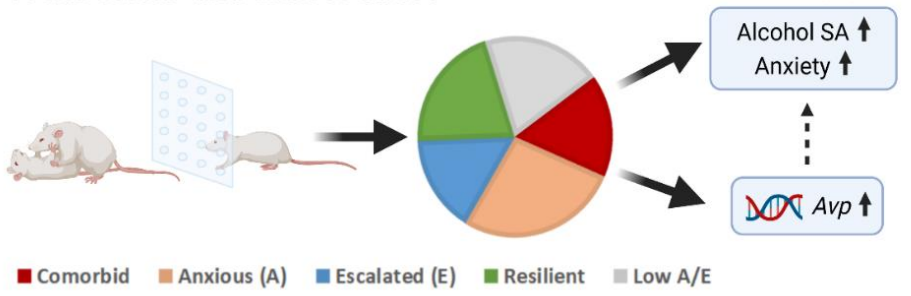

Figure 10. Social defeat- and witness stress induce a comorbid escalation of alcohol self-administration (SA) and increased anxiety-like behavior in a susceptible subpopulation of rats. This subpopulation had a strong upregulation of amygdala Avp expression, that positively correlated with the magnitude of the comorbidity.

\subsubsection{Paper III: conclusion}

In Paper III, we demonstrate that social defeat- and witness stress induce long-term comorbid increases in anxiety-like behavior and escalation of alcohol intake. Similar to the clinical situation, only a subpopulation of rats shows susceptibility to the stress, supporting a translational validity of this model. Comorbid SDS and witness rats have largely different gene expression profiles within the AMG, suggesting that the two stressors in part produce their behavioral consequences through different mechanisms. However, our results also identify a shared mechanism, with a strong upregulation of $A v p$ and $O x t$ in the AMG. Upregulation of these transcripts correlated positively with the magnitude of comorbidity in SDS rats, and to a lesser extent in witness rats. Together, these data provide novel insights into the neurobiological substrates that underlie individual variation in susceptibility to comorbid alcohol- and anxiety-related behaviors. 


\section{CONCLUDING REMARKS}

In this doctoral thesis, we investigated mechanisms of alcohol- and anxiety-related behaviors in rats. We functionally linked two genes, Syt1 and Prdm2, to a dysregulated function of PL-BLA projecting neurons in behaviors that model critical aspects of AUD and anxiety disorders, respectively. In a third study, we identified vasopressin expression within the amygdala as a possible neurobiological substrate of individual susceptibility for stress-induced, co-occurring escalation of alcohol intake and anxiety-like behavior.

Contribution of epigenetic mechanisms to alcohol-induced psychopathology. Heavy alcohol use is an important risk factor for the development of AUD and anxiety disorders ${ }^{1,87}$. Our lab previously identified DNA hypermethylation as a mechanism behind alcohol-induced downregulation of prelimbic Syt1 and Prdm2. Specifically, treatment with the DNMT inhibitor RG108 restored expression levels of these transcripts, and partially rescued the behavioral consequences of alcohol-dependence ${ }^{67}$. In a subsequent study, our lab then demonstrated a functional role of PRDM2 in alcohol-related behaviors ${ }^{69}$. In the work that constitutes this thesis, we have further explored the behavioral consequences of Syt1 and Prdm2 downregulation, and identified the PL-BLA projection as a key circuit within which the gene products encoded by these transcripts act to regulate alcohol- and anxietyrelated behaviors, respectively. A study by Xu et al. has also implicated SYT1 in anxiety-related behavior, where a downregulation resulted in generalization of fear memory ${ }^{192}$. Together, these findings support the notion that alcohol-induced DNA-hypermethylation promotes both alcohol- and anxiety-related behaviors through prelimbic downregulation of Syt1 and Prdm2. The findings highlight the contribution of epigenetic mechanisms in mediating behavioral consequences of alcoholdependence, and identify specific downstream target genes whose expression is influenced by alcoholinduced epigenetic reprogramming to mediate long term behavioral consequences.

Individual vulnerability to stress effects that promote the development of alcohol addiction and anxiety disorders. Stress promotes the development of both alcohol addiction and anxiety disorders, and epidemiological data highlight an individual variation in susceptibility and resilience to stressinduced psychopathology $y^{58}$. Using a model of social defeat- and witness stress, we recapitulated in rats the broad range of individual stress responses observed in human populations, and identified amygdala Avp as a possible shared mediating factor for responses to physical and emotional stress. Vasopressin has been linked to both anxiety- and alcohol-related behaviors in rodents ${ }^{182,183}$ and in humans it has been associated with increased stress reactivity ${ }^{185-188}$. Our results support a role of Avp in the individual vulnerability to develop stress-induced psychopathology. The causal role of Avp upregulation in stress-induced escalation of alcohol intake and anxiety-like behavior identified by our work remains to be established.

Clinically, only a subset of users transitions to compulsive drug use ${ }^{193}$, but nearly all rats learn to selfadminister drugs ${ }^{74,75}$. Escalation of alcohol consumption is only one of the clinical features observed in patients with AUD. In addition to escalated self-administration, it may be important to study how other elements of addiction are influenced by stress ${ }^{83,84,194}$. In rats exposed to social defeat- and witness stress, it may be informative to assess alcohol addiction-related behaviors such as compulsive-like alcohol taking and stress-induced reinstatement ${ }^{86}$. Similarly, it may be of interest to further characterize the anxiety-like behaviors observed following social defeat- and witness stress, using other models of anxiety, including models that rely on learned rather than innate fear ${ }^{195}$.

Sex differences in alcohol- and anxiety-related behaviors. The prevalence of AUD is higher in men than in women, and males account for more of the total alcohol-related harm than women, including 
deaths ${ }^{11}$. However, the gap in AUD prevalence between men and women has decreased over time, and women have a higher prevalence of anxiety disorders as well as co-occurring AUD and anxiety disorders ${ }^{13}$. Future work will therefore need to establish to what extent our findings can be generalized to females.

Prdm2 has previously been shown to interact with the estrogen receptor ${ }^{196,197}$, and its role may be of particular interest to investigate in female rats. In our model of co-occurring alcohol- and anxietyrelated behavior, one of the aims was to investigate whether comorbid behavioral characteristics induced by the two different stressors are promoted by shared molecular mechanisms. Unfortunately, the SDS model cannot be readily applied to females, as females do not display territorial aggression ${ }^{198,199}$. We therefore focused on males to allow a direct comparison between social defeatand witness stressed rats. Recent work by Finnel et al. has demonstrated that female witness rats develop similar depression-like behaviors as male rats ${ }^{200}$, and it would now be possible to compare the gene expression profiles of male and female witness-stressed rats in a future study.

Clinical implications. More broadly, our findings point to the possibility that epigenetic mechanisms play an important role in the neurobiology of AUD. Identifying the downstream molecular targets of alcohol-induced epigenetic transcriptome reprogramming that play a causal role for addiction-related behaviors offers a strategy for novel therapeutic target identification. Alternatively, novel therapeutics may be possible to develop that directly target the epigenetic machinery. This may allow a rescue of the broad and persistent gene expression changes found in AUD and anxiety disorders, thereby offering disease-modifying rather than merely symptomatic treatments. Against expectations, experience from the cancer field indicates that medications targeting the epigenetic machinery may be safe and well tolerated ${ }^{201}$. 


\section{ACKNOWLEDGEMENTS}

There are many whom I would like to thank for their contributions to this thesis and to my time in Linköping.

First and foremost, to my main supervisor Estelle Barbier for the countless hours you have spent mentoring me. I would not have half my skills if it were not for you. Hopefully you will find someone else to do your taxes for you when I leave...

To Markus Heilig, for your infinite wisdom and for giving me this opportunity. Annika Thorsell, for having picked me up as a student and brought me into neuroscience in the first place.

To the best colleagues one could possibly have, realistically speaking (just kidding, you're practically family): Esi Domi, Messi Domi, Sanne Toivainen, Sonja Toivainen, Estêlle Barbier, Lovisa Holm, Li Xu, Kanat Chanthongdee, Andrea Coppola, Michele Petrella, Eric \& Gaëlle Augier, Joost Wiskerke, Björn Granseth, Ann-Charlotte Johansson, Ulla Svensson Bater, Anna Asratian, (Daniel Nätt). Also, remind me to buy you a vegetarian cookbook Li, don't eat the rats...

To all of CSAN and to the TRIP-C people for somehow finding a use even for humans in psychiatric research... Take care of the colonel, princess.

To former lab members, students, and all the people on Floor 12. Corona or not, I believe there is a tower to climb David. Consider it an invitation, floor 12.

To all external collaborators on these projects: Louise Adermark, Ana Domi, Francesco Gobbo, Claudio Cantù, Simon Söderholm, your expertise was as much of a learning experience for me as it was crucial for the projects!

To Stefan Ljunggren, for your long friendship and for teaching me proteomics (hey, that ended up in Science!). To all my friends and family for your support and your company.

And most importantly to my wife, Angelica, for all your support, love, and patience throughout the inconvenient hours that is science. I love you very much.

And to you, Andrew, if you made it this far... 


\section{RefERENCES}

1 Collaborators, G. B. D. A. Alcohol use and burden for 195 countries and territories, 1990-2016: a systematic analysis for the Global Burden of Disease Study 2016. Lancet 392, 1015-1035, doi:10.1016/S0140-6736(18)31310-2 (2018).

2 Carvalho, A. F., Heilig, M., Perez, A., Probst, C. \& Rehm, J. Alcohol use disorders. Lancet 394, 781-792, doi:10.1016/S0140-6736(19)31775-1 (2019).

3 Heilig, M. et al. Addiction as a brain disease revised: why it still matters, and the need for consilience. Neuropsychopharmacology, doi:10.1038/s41386-020-00950-y (2021).

4 Heilig, M., Augier, E., Pfarr, S. \& Sommer, W. H. Developing neuroscience-based treatments for alcohol addiction: A matter of choice? Translational psychiatry 9, 255, doi:10.1038/s41398-019-0591-6 (2019).

5 Boileau, l. et al. Alcohol promotes dopamine release in the human nucleus accumbens. Synapse 49, 226-231, doi:10.1002/syn.10226 (2003).

6 Gilman, J. M., Ramchandani, V. A., Davis, M. B., Bjork, J. M. \& Hommer, D. W. Why we like to drink: a functional magnetic resonance imaging study of the rewarding and anxiolytic effects of alcohol. $J$. Neurosci. 28, 4583-4591, doi:10.1523/JNEUROSCI.0086-08.2008 (2008).

7 Ramchandani, V. A. et al. A genetic determinant of the striatal dopamine response to alcohol in men. Mol. Psychiatry 16, 809-817, doi:10.1038/mp.2010.56 (2011).

8 Koob, G. F. \& Le Moal, M. Plasticity of reward neurocircuitry and the 'dark side' of drug addiction. Nat. Neurosci. 8, 1442-1444, doi:10.1038/nn1105-1442 (2005).

9 Anthony, J. C., Warner, L. A. \& Kessler, R. C. Comparative epidemiology of dependence on tobacco, alcohol, controlled substances, and inhalants: Basic findings from the National Comorbidity Survey. Experimental and clinical psychopharmacology 2, 244-268, doi:10.1037/1064-1297.2.3.244 (1994). Cheng, A. T., Gau, S. F., Chen, T. H., Chang, J. C. \& Chang, Y. T. A 4-year longitudinal study on risk factors for alcoholism. Arch Gen Psychiatry 61, 184-191, doi:10.1001/archpsyc.61.2.184 (2004). White, A. et al. Converging Patterns of Alcohol Use and Related Outcomes Among Females and Males in the United States, 2002 to 2012. Alcohol Clin Exp Res 39, 1712-1726, doi:10.1111/acer.12815 (2015).

12 Urban, N. B. et al. Sex differences in striatal dopamine release in young adults after oral alcohol challenge: a positron emission tomography imaging study with $[(11) \mathrm{C}]$ raclopride. Biol. Psychiatry 68, 689-696, doi:10.1016/j.biopsych.2010.06.005 (2010). Kessler, R. C. et al. Lifetime co-occurrence of DSM-III-R alcohol abuse and dependence with other psychiatric disorders in the National Comorbidity Survey. Arch Gen Psychiatry 54, 313-321, doi:10.1001/archpsyc.1997.01830160031005 (1997).

14 Erol, A. \& Karpyak, V. M. Sex and gender-related differences in alcohol use and its consequences: Contemporary knowledge and future research considerations. Drug Alcohol Depend 156, 1-13, doi:10.1016/j.drugalcdep.2015.08.023 (2015). Smith, J. P. \& Randall, C. L. Anxiety and alcohol use disorders: comorbidity and treatment considerations. Alcohol Res 34, 414-431 (2012). Jonas, D. E. et al. Pharmacotherapy for Adults With Alcohol Use Disorders in Outpatient Settings A Systematic Review and Meta-analysis. Jama-J Am Med Assoc 311, 1889-1900, doi:DOI 10.1001/jama.2014.3628 (2014). Spanagel, R. Alcoholism: a systems approach from molecular physiology to addictive behavior. Physiol. Rev. 89, 649-705, doi:10.1152/physrev.00013.2008 (2009). Gilpin, N. W., Herman, M. A. \& Roberto, M. The central amygdala as an integrative hub for anxiety and alcohol use disorders. Biol. Psychiatry 77, 859-869, doi:10.1016/j.biopsych.2014.09.008 (2015). Gilpin, N. W. \& Roberto, M. Neuropeptide modulation of central amygdala neuroplasticity is a key mediator of alcohol dependence. Neurosci. Biobehav. Rev. 36, 873-888, doi:10.1016/j.neubiorev.2011.11.002 (2012). Goldstein, R. Z. \& Volkow, N. D. Dysfunction of the prefrontal cortex in addiction: neuroimaging findings and clinical implications. Nat Rev Neurosci 12, 652-669, doi:10.1038/nrn3119 (2011). McGarry, L. M. \& Carter, A. G. Prefrontal Cortex Drives Distinct Projection Neurons in the Basolateral Amygdala. Cell Rep 21, 1426-1433, doi:10.1016/j.celrep.2017.10.046 (2017). Peters, J., Kalivas, P. W. \& Quirk, G. J. Extinction circuits for fear and addiction overlap in prefrontal cortex. Learn Mem 16, 279-288, doi:10.1101/Im.1041309 (2009). 
Patkar, O. L., Belmer, A., Holgate, J. Y., Klenowski, P. M. \& Bartlett, S. E. Modulation of serotonin and noradrenaline in the BLA by pindolol reduces long-term ethanol intake. Addict Biol 24, 652-663, doi:10.1111/adb.12630 (2019).

Purohit, K. et al. Pharmacogenetic Manipulation of the Nucleus Accumbens Alters Binge-Like Alcohol Drinking in Mice. Alcohol Clin Exp Res 42, 879-888, doi:10.1111/acer.13626 (2018). Craske, M. G. et al. Anxiety disorders. Nat Rev Dis Primers 3, 17024, doi:10.1038/nrdp.2017.24 (2017). Banerjee, S. B., Morrison, F. G. \& Ressler, K. J. Genetic approaches for the study of PTSD: Advances and challenges. Neurosci Lett 649, 139-146, doi:10.1016/j.neulet.2017.02.058 (2017). LeDoux, J. E. Emotion circuits in the brain. Annu Rev Neurosci 23, 155-184, doi:10.1146/annurev.neuro.23.1.155 (2000).

Grant, B. F. et al. Prevalence and co-occurrence of substance use disorders and independent mood and anxiety disorders: results from the National Epidemiologic Survey on Alcohol and Related Conditions. Arch. Gen. Psychiatry 61, 807-816, doi:10.1001/archpsyc.61.8.807 (2004). Khantzian, E. J. The self-medication hypothesis of substance use disorders: a reconsideration and recent applications. Harv. Rev. Psychiatry 4, 231-244, doi:10.3109/10673229709030550 (1997). Bibb, J. L. \& Chambless, D. L. Alcohol use and abuse among diagnosed agoraphobics. Behav Res Ther 24, 49-58, doi:10.1016/0005-7967(86)90149-x (1986). Smail, P., Stockwell, T., Canter, S. \& Hodgson, R. Alcohol dependence and phobic anxiety states. I. A prevalence study. Br J Psychiatry 144, 53-57, doi:10.1192/bjp.144.1.53 (1984). Thomas, S. E., Randall, C. L. \& Carrigan, M. H. Drinking to cope in socially anxious individuals: a controlled study. Alcohol Clin Exp Res 27, 1937-1943, doi:10.1097/01.ALC.0000100942.30743.8C

(2003). substance use disorders among young persons: results of a 21-year longitudinal study. J Psychiatr Res 38, 295-304, doi:10.1016/j.jpsychires.2003.09.002 (2004). Brady, K. T. \& Back, S. E. Childhood trauma, posttraumatic stress disorder, and alcohol dependence. Alcohol Res 34, 408-413 (2012).

Roberts, N. P., Roberts, P. A., Jones, N. \& Bisson, J. I. Psychological interventions for post-traumatic stress disorder and comorbid substance use disorder: A systematic review and meta-analysis. Clin Psychol Rev 38, 25-38, doi:10.1016/j.cpr.2015.02.007 (2015). Serv 34, 24-30 (1996). Zegel, M., Tran, J. K. \& Vujanovic, A. A. Posttraumatic stress, alcohol use, and alcohol use motives among firefighters: The role of distress tolerance. Psychiatry Res 282, 112633, doi:10.1016/j.psychres.2019.112633 (2019). Perlman, S. E. et al. Short-term and medium-term health effects of 9/11. Lancet 378, 925-934, doi:10.1016/S0140-6736(11)60967-7 (2011). van Wingen, G. A., Geuze, E., Vermetten, E. \& Fernandez, G. Perceived threat predicts the neural sequelae of combat stress. Mol Psychiatry 16, 664-671, doi:10.1038/mp.2010.132 (2011). Sinha, R. Chronic stress, drug use, and vulnerability to addiction. Ann. N. Y. Acad. Sci. 1141, 105-130, doi:10.1196/annals.1441.030 (2008). Ruisoto, P. \& Contador, I. The role of stress in drug addiction. An integrative review. Physiol. Behav. 202, 62-68, doi:10.1016/j.physbeh.2019.01.022 (2019). Holmes, A. et al. Chronic alcohol remodels prefrontal neurons and disrupts NMDAR-mediated fear extinction encoding. Nat Neurosci 15, 1359-1361, doi:10.1038/nn.3204 (2012). Heilig, M., Epstein, D. H., Nader, M. A. \& Shaham, Y. Time to connect: bringing social context into addiction neuroscience. Nat Rev Neurosci 17, 592-599, doi:10.1038/nrn.2016.67 (2016). Cole, G., Tucker, L. \& Friedman, G. M. Relationships among measures of alcohol drinking behavior, lifeevents and perceived stress. Psychol Rep 67, 587-591, doi:10.2466/pr0.1990.67.2.587 (1990). King, A. C., Bernardy, N. C. \& Hauner, K. Stressful events, personality, and mood disturbance: gender differences in alcoholics and problem drinkers. Addict Behav 28, 171-187, doi:10.1016/s03064603(01)00264-7 (2003). consumption in healthy subjects. Alcohol Clin Exp Res 27, 1270-1277, doi:10.1097/01.ALC.0000081617.37539.D6 (2003). 

anxiety and depression symptoms. Occup Med (Lond) 65, 110-116, doi:10.1093/occmed/kqu181 (2015). brain reward regions. Cell 131, 391-404, doi:10.1016/j.cell.2007.09.018 (2007).

Berton, O. et al. Essential role of BDNF in the mesolimbic dopamine pathway in social defeat stress. Science 311, 864-868, doi:10.1126/science.1120972 (2006). Bjorkqvist, K. Social defeat as a stressor in humans. Physiol Behav 73, 435-442, doi:10.1016/s00319384(01)00490-5 (2001). Blanchard, R. J., McKittrick, C. R. \& Blanchard, D. C. Animal models of social stress: effects on behavior and brain neurochemical systems. Physiol Behav 73, 261-271, doi:10.1016/s0031-9384(01)00449-8 (2001). Bosch-Bouju, C., Larrieu, T., Linders, L., Manzoni, O. J. \& Laye, S. Endocannabinoid-Mediated Plasticity in Nucleus Accumbens Controls Vulnerability to Anxiety after Social Defeat Stress. Cell Rep 16, 12371242, doi:10.1016/j.celrep.2016.06.082 (2016). Macedo, G. C. et al. Consequences of continuous social defeat stress on anxiety- and depressive-like behaviors and ethanol reward in mice. Horm Behav 97, 154-161, doi:10.1016/j.yhbeh.2017.10.007 (2018). Hammels, C. et al. Defeat stress in rodents: From behavior to molecules. Neurosci Biobehav Rev 59, 111-140, doi:10.1016/j.neubiorev.2015.10.006 (2015). Venzala, E., Garcia-Garcia, A. L., Elizalde, N., Delagrange, P. \& Tordera, R. M. Chronic social defeat stress model: behavioral features, antidepressant action, and interaction with biological risk factors. Psychopharmacology (Berl) 224, 313-325, doi:10.1007/s00213-012-2754-5 (2012). Spanagel, R., Noori, H. R. \& Heilig, M. Stress and alcohol interactions: animal studies and clinical significance. Trends Neurosci. 37, 219-227, doi:10.1016/j.tins.2014.02.006 (2014). Kessler, R. C. et al. Trauma and PTSD in the WHO World Mental Health Surveys. Eur J Psychotraumatol 8, 1353383, doi:10.1080/20008198.2017.1353383 (2017). Enman, N. M., Zhang, Y. \& Unterwald, E. M. Connecting the pathology of posttraumatic stress and substance use disorders: monoamines and neuropeptides. Pharmacol Biochem Behav 117, 61-69, doi:10.1016/j.pbb.2013.12.001 (2014). Lyko, F. The DNA methyltransferase family: a versatile toolkit for epigenetic regulation. Nat Rev Genet 19, 81-92, doi:10.1038/nrg.2017.80 (2018). Szyf, M. Epigenetics, DNA methylation, and chromatin modifying drugs. Annu. Rev. Pharmacol. Toxicol. 49, 243-263, doi:10.1146/annurev-pharmtox-061008-103102 (2009). Farris, S. P. \& Mayfield, R. D. RNA-Seq reveals novel transcriptional reorganization in human alcoholic brain. Int Rev Neurobiol 116, 275-300, doi:10.1016/B978-0-12-801105-8.00011-4 (2014). Zovkic, I. B. \& Sweatt, J. D. Epigenetic mechanisms in learned fear: implications for PTSD. Neuropsychopharmacology 38, 77-93, doi:10.1038/npp.2012.79 (2013).

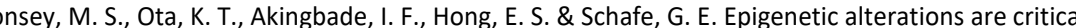
for fear memory consolidation and synaptic plasticity in the lateral amygdala. PLoS One 6, e19958, doi:10.1371/journal.pone.0019958 (2011). Weaver, I. C. et al. Epigenetic programming by maternal behavior. Nat Neurosci 7, 847-854, doi:10.1038/nn1276 (2004). Murgatroyd, C. \& Spengler, D. Epigenetics of early child development. Front Psychiatry 2, 16, doi:10.3389/fpsyt.2011.00016 (2011). Klengel, T. \& Binder, E. B. Epigenetics of Stress-Related Psychiatric Disorders and Gene x Environment Interactions. Neuron 86, 1343-1357, doi:10.1016/j.neuron.2015.05.036 (2015). Barbier, E. et al. DNA methylation in the medial prefrontal cortex regulates alcohol-induced behavior and plasticity. J Neurosci 35, 6153-6164, doi:10.1523/JNEUROSCI.4571-14.2015 (2015). Warnault, V., Darcq, E., Levine, A., Barak, S. \& Ron, D. Chromatin remodeling--a novel strategy to control excessive alcohol drinking. Transl Psychiatry 3, e231, doi:10.1038/tp.2013.4 (2013). Barbier, E. et al. Dependence-induced increase of alcohol self-administration and compulsive drinking mediated by the histone methyltransferase PRDM2. Mol Psychiatry 22, 1746-1758, doi:10.1038/mp.2016.131 (2017). 
Nielsen, S. J. et al. Rb targets histone H3 methylation and HP1 to promoters. Nature 412, 561-565, doi:10.1038/35087620 (2001).

Institute, W. Archive, <https://web.archive.org/web/20081017070234/http://www.wistar.org/about wistar/history.html> (2005).

Bryda, E. C. The Mighty Mouse: the impact of rodents on advances in biomedical research. Mo Med 110, 207-211 (2013).

Weeks, J. R. Experimental morphine addiction: method for automatic intravenous injections in unrestrained rats. Science 138, 143-144, doi:10.1126/science.138.3537.143 (1962).

Augier, E., Dulman, R. S., Singley, E. \& Heilig, M. A Method for Evaluating the Reinforcing Properties of Ethanol in Rats without Water Deprivation, Saccharin Fading or Extended Access Training. J Vis Exp, doi:10.3791/53305 (2017).

Reinhard, C. \& Wolffgramm, J. Long-term voluntary consumption of MDMA and THC in rats is modified by individual and situational factors. Addict Biol 11, 131-144, doi:10.1111/j.1369-1600.2006.00022.x (2006).

Do-Monte, F. H., Quinones-Laracuente, K. \& Quirk, G. J. A temporal shift in the circuits mediating retrieval of fear memory. Nature 519, 460-463, doi:10.1038/nature14030 (2015).

Morrison, F. G. \& Ressler, K. J. From the neurobiology of extinction to improved clinical treatments. Depress Anxiety 31, 279-290, doi:10.1002/da.22214 (2014).

Venniro, M. et al. Volitional social interaction prevents drug addiction in rat models. Nat Neurosci 21, 1520-1529, doi:10.1038/s41593-018-0246-6 (2018).

Steinman, M. Q. et al. Importance of sex and trauma context on circulating cytokines and amygdalar GABAergic signaling in a comorbid model of posttraumatic stress and alcohol use disorders. Mol Psychiatry, doi:10.1038/s41380-020-00920-2 (2020).

Careaga, M. B. L., Girardi, C. E. N. \& Suchecki, D. Variability in response to severe stress: highly reactive rats exhibit changes in fear and anxiety-like behavior related to distinct neuronal co-activation patterns. Behav Brain Res 373, 112078, doi:10.1016/j.bbr.2019.112078 (2019).

Anthony, J. C., Warner, L. A., \& Kessler, R. C. Comparative epidemiology of dependence on tobacco, alcohol, controlled substances, and inhalants: Basic findings from the National Comorbidity Survey. Experimental and Clinical Psychopharmacology 2, 244-268 (1994).

Augier, E. et al. A molecular mechanism for choosing alcohol over an alternative reward. Science 360, 1321-1326, doi:10.1126/science.aao1157 (2018).

Ahmed, S. H. Validation crisis in animal models of drug addiction: beyond non-disordered drug use toward drug addiction. Neurosci Biobehav Rev 35, 172-184, doi:10.1016/j.neubiorev.2010.04.005 (2010).

Chen, B. T. et al. Cocaine but not natural reward self-administration nor passive cocaine infusion produces persistent LTP in the VTA. Neuron 59, 288-297, doi:10.1016/j.neuron.2008.05.024 (2008). American Psychiatric Association: Diagnostic and Statistical Manual of Mental Disorders: Diagnostic and Statistical Manual of Mental Disorders. Fifth Edition edn, (American Psychiatric Association, 2013).

Rehm, J. et al. The relationship between different dimensions of alcohol use and the burden of disease-an update. Addiction 112, 968-1001, doi:10.1111/add.13757 (2017).

Stafford, D., LeSage, M. G. \& Glowa, J. R. Progressive-ratio schedules of drug delivery in the analysis of drug self-administration: a review. Psychopharmacology (Berl) 139, 169-184, doi:10.1007/s002130050702 (1998).

Marti-Prats, L. et al. Baclofen decreases compulsive alcohol drinking in rats characterized by reduced levels of GAT-3 in the central amygdala. Addict Biol, e13011, doi:10.1111/adb.13011 (2021).

Carneiro, C. F. D., Moulin, T. C., Macleod, M. R. \& Amaral, O. B. Effect size and statistical power in the rodent fear conditioning literature - A systematic review. PLoS One 13, e0196258,

doi:10.1371/journal.pone.0196258 (2018).

Johansen, J. P., Cain, C. K., Ostroff, L. E. \& LeDoux, J. E. Molecular mechanisms of fear learning and memory. Cell 147, 509-524, doi:10.1016/j.cell.2011.10.009 (2011).

Blanchard, R. J. \& Blanchard, D. C. Crouching as an index of fear. J Comp Physiol Psychol 67, 370-375, doi:10.1037/h0026779 (1969).

Semon, R. Die Mneme. (G. Allen \& Unwin Itd, The Macmillan company, 1921).

Josselyn, S. A. \& Tonegawa, S. Memory engrams: Recalling the past and imagining the future. Science 367, doi:10.1126/science.aaw4325 (2020). 

understanding of neural circuits underlying fear behaviors. Neurobiol Learn Mem 135, 27-39, doi:10.1016/j.nlm.2016.07.025 (2016).

96 Sial, O. K., Warren, B. L., Alcantara, L. F., Parise, E. M. \& Bolanos-Guzman, C. A. Vicarious social defeat stress: Bridging the gap between physical and emotional stress. J Neurosci Methods 258, 94-103, doi:10.1016/j.jneumeth.2015.10.012 (2016). Kudryavtseva, N. N. \& Bakshtanovskaya, I. V. Experience of defeat increases the susceptibility to catatonic - like state in mice. Behav Processes 20, 139-149, doi:10.1016/0376-6357(89)90019-3 (1989). Bolhuis, J. J., Fitzgerald, R. E., Dijk, D. J. \& Koolhaas, J. M. The corticomedial amygdala and learning in an agonistic situation in the rat. Physiol Behav 32, 575-579, doi:10.1016/0031-9384(84)90311-1 (1984).

99 Tidey, J. W. \& Miczek, K. A. Acquisition of cocaine self-administration after social stress: role of accumbens dopamine. Psychopharmacology (Berl) 130, 203-212, doi:10.1007/s002130050230 (1997). Hollis, F. \& Kabbaj, M. Social defeat as an animal model for depression. ILAR J 55, 221-232, doi:10.1093/ilar/ilu002 (2014).

101 Huhman, K. L. Social conflict models: can they inform us about human psychopathology? Horm Behav 50, 640-646, doi:10.1016/j.yhbeh.2006.06.022 (2006).

102 Beery, A. K. \& Kaufer, D. Stress, social behavior, and resilience: insights from rodents. Neurobiol Stress 1, 116-127, doi:10.1016/j.ynstr.2014.10.004 (2015).

103 Newman, E. L., Leonard, M. Z., Arena, D. T., de Almeida, R. M. M. \& Miczek, K. A. Social defeat stress and escalation of cocaine and alcohol consumption: Focus on CRF. Neurobiol Stress 9, 151-165, doi:10.1016/j.ynstr.2018.09.007 (2018).

104 Langford, D. J. et al. Social modulation of pain as evidence for empathy in mice. Science 312, 19671970, doi:10.1126/science.1128322 (2006).

105 Gonzalez-Liencres, C., Juckel, G., Tas, C., Friebe, A. \& Brune, M. Emotional contagion in mice: the role of familiarity. Behav Brain Res 263, 16-21, doi:10.1016/j.bbr.2014.01.020 (2014).

106 Jeon, D. et al. Observational fear learning involves affective pain system and Cav1.2 Ca2+ channels in ACC. Nat Neurosci 13, 482-488, doi:10.1038/nn.2504 (2010).

107 Jones, C. E. \& Monfils, M. H. Dominance status predicts social fear transmission in laboratory rats. Anim Cogn 19, 1051-1069, doi:10.1007/s10071-016-1013-2 (2016).

108 Knapska, E., Mikosz, M., Werka, T. \& Maren, S. Social modulation of learning in rats. Learn Mem 17, 35-42, doi:10.1101/Im.1670910 (2010).

109 Lidhar, N. K., Insel, N., Dong, J. Y. \& Takehara-Nishiuchi, K. Observational fear learning in degus is correlated with temporal vocalization patterns. Behav Brain Res 332, 362-371, doi:10.1016/j.bbr.2017.06.011 (2017).

110 Hashikawa, K., Hashikawa, Y., Lischinsky, J. \& Lin, D. The Neural Mechanisms of Sexually Dimorphic Aggressive Behaviors. Trends Genet 34, 755-776, doi:10.1016/j.tig.2018.07.001 (2018).

111 Hilke, S., Holm, L., Man, K., Hokfelt, T. \& Theodorsson, E. Rapid change of neuropeptide Y levels and gene-expression in the brain of ovariectomized mice after administration of 17beta-estradiol. Neuropeptides 43, 327-332, doi:10.1016/j.npep.2009.04.005 (2009).

112 Pellow, S., Chopin, P., File, S. E. \& Briley, M. Validation of open:closed arm entries in an elevated plusmaze as a measure of anxiety in the rat. $J$ Neurosci Methods 14, 149-167, doi:10.1016/01650270(85)90031-7 (1985).

113 Walf, A. A. \& Frye, C. A. The use of the elevated plus maze as an assay of anxiety-related behavior in rodents. Nat Protoc 2, 322-328, doi:10.1038/nprot.2007.44 (2007).

114 Montgomery, K. C. The relation between fear induced by novel stimulation and exploratory behavior. $J$ Comp Physiol Psychol 48, 254-260, doi:10.1037/h0043788 (1955).

115 Handley, S. L. \& Mithani, S. Effects of alpha-adrenoceptor agonists and antagonists in a mazeexploration model of 'fear'-motivated behaviour. Naunyn Schmiedebergs Arch Pharmacol 327, 1-5, doi:10.1007/BF00504983 (1984).

116 Rodgers, R. J. et al. Corticosterone response to the plus-maze: high correlation with risk assessment in rats and mice. Physiol Behav 68, 47-53, doi:10.1016/s0031-9384(99)00140-7 (1999).

117 Domi, E. et al. Preclinical evaluation of the kappa-opioid receptor antagonist CERC-501 as a candidate therapeutic for alcohol use disorders. Neuropsychopharmacology 43, 1805-1812, doi:10.1038/s41386018-0015-y (2018).

118 Antunes, M. \& Biala, G. The novel object recognition memory: neurobiology, test procedure, and its modifications. Cogn Process 13, 93-110, doi:10.1007/s10339-011-0430-z (2012). 
119 Fire, A. et al. Potent and specific genetic interference by double-stranded RNA in Caenorhabditis elegans. Nature 391, 806-811, doi:10.1038/35888 (1998).

120 Moore, C. B., Guthrie, E. H., Huang, M. T. \& Taxman, D. J. Short hairpin RNA (shRNA): design, delivery, and assessment of gene knockdown. Methods Mol Biol 629, 141-158, doi:10.1007/978-1-60761-6573_10 (2010).

121 Finnegan, E. F. \& Pasquinelli, A. E. MicroRNA biogenesis: regulating the regulators. Crit Rev Biochem Mol Biol 48, 51-68, doi:10.3109/10409238.2012.738643 (2013).

122 Branda, C. S. \& Dymecki, S. M. Talking about a revolution: The impact of site-specific recombinases on genetic analyses in mice. Dev Cell 6, 7-28, doi:10.1016/s1534-5807(03)00399-x (2004).

123 Gompf, H. S., Budygin, E. A., Fuller, P. M. \& Bass, C. E. Targeted genetic manipulations of neuronal subtypes using promoter-specific combinatorial AAVs in wild-type animals. Front Behav Neurosci $\mathbf{9}$, 152, doi:10.3389/fnbeh.2015.00152 (2015).

124 Sternberg, N. \& Hamilton, D. Bacteriophage P1 site-specific recombination. I. Recombination between loxP sites. J Mol Biol 150, 467-486, doi:10.1016/0022-2836(81)90375-2 (1981).

125 Aschauer, D. F., Kreuz, S. \& Rumpel, S. Analysis of transduction efficiency, tropism and axonal transport of AAV serotypes 1, 2, 5, 6, 8 and 9 in the mouse brain. PLoS One 8, e76310, doi:10.1371/journal.pone.0076310 (2013).

126 Le Bec, C. \& Douar, A. M. Gene therapy progress and prospects--vectorology: design and production of expression cassettes in AAV vectors. Gene Ther 13, 805-813, doi:10.1038/sj.gt.3302724 (2006).

127 Tervo, D. G. et al. A Designer AAV Variant Permits Efficient Retrograde Access to Projection Neurons. Neuron 92, 372-382, doi:10.1016/j.neuron.2016.09.021 (2016).

128 Chen, T. W. et al. Ultrasensitive fluorescent proteins for imaging neuronal activity. Nature 499, 295300, doi:10.1038/nature12354 (2013).

129 Resendez, S. L. \& Stuber, G. D. In vivo calcium imaging to illuminate neurocircuit activity dynamics underlying naturalistic behavior. Neuropsychopharmacology 40, 238-239, doi:10.1038/npp.2014.206 (2015).

130 Wang, X., Zhang, C., Szabo, G. \& Sun, Q. Q. Distribution of CaMKIlalpha expression in the brain in vivo, studied by CaMKIlalpha-GFP mice. Brain Res 1518, 9-25, doi:10.1016/j.brainres.2013.04.042 (2013).

131 Bortolotto, Z. A., Amici, M., Anderson, W. W., Isaac, J. T. \& Collingridge, G. L. Synaptic plasticity in the hippocampal slice preparation. Curr Protoc Neurosci Chapter 6, Unit 6 13, doi:10.1002/0471142301.ns0613s54 (2011).

132 Patch-Clamp Methods and Protocols. Vol. 2nd ed. (Springer Protocols, 2014).

133 Patch-Clamp Analysis. Vol. 35 (Humana Press Inc., 2002).

134 Herman, M. A. et al. Glutamatergic transmission in the central nucleus of the amygdala is selectively altered in Marchigian Sardinian alcohol-preferring rats: Alcohol and CRF effects. Neuropharmacology 102, 21-31, doi:10.1016/j.neuropharm.2015.10.027 (2016).

135 Regehr, W. G. Short-term presynaptic plasticity. Cold Spring Harb Perspect Biol 4, a005702, doi:10.1101/cshperspect.a005702 (2012).

136 Nagalakshmi, U., Waern, K. \& Snyder, M. RNA-Seq: a method for comprehensive transcriptome analysis. Curr Protoc Mol Biol Chapter 4, Unit 411 11-13, doi:10.1002/0471142727.mb0411s89 (2010).

137 Heiman, M., Kulicke, R., Fenster, R. J., Greengard, P. \& Heintz, N. Cell type-specific mRNA purification by translating ribosome affinity purification (TRAP). Nat Protoc 9, 1282-1291, doi:10.1038/nprot.2014.085 (2014).

138 Talla, S. B. et al. Immuno-oncology gene expression profiling of formalin-fixed and paraffin-embedded clear cell renal cell carcinoma: Performance comparison of the NanoString nCounter technology with targeted RNA sequencing. Genes Chromosomes Cancer 59, 406-416, doi:10.1002/gcc.22843 (2020).

139 Schmidt, S. et al. Comparison of GeneChip, nCounter, and Real-Time PCR-Based Gene Expressions Predicting Locoregional Tumor Control after Primary and Postoperative Radiochemotherapy in Head and Neck Squamous Cell Carcinoma. J Mol Diagn 22, 801-810, doi:10.1016/j.jmoldx.2020.03.005 (2020).

140 Goytain, A. \& Ng, T. NanoString nCounter Technology: High-Throughput RNA Validation. Methods Mol Biol 2079, 125-139, doi:10.1007/978-1-4939-9904-0_10 (2020).

141 Livak, K. J. \& Schmittgen, T. D. Analysis of relative gene expression data using real-time quantitative PCR and the 2(-Delta Delta C(T)) Method. Methods 25, 402-408, doi:10.1006/meth.2001.1262 (2001).

142 Wang, F. et al. RNAscope: a novel in situ RNA analysis platform for formalin-fixed, paraffin-embedded tissues. J Mol Diagn 14, 22-29, doi:10.1016/j.jmoldx.2011.08.002 (2012). 
143 Rubio, F. J. et al. Context-induced reinstatement of methamphetamine seeking is associated with unique molecular alterations in Fos-expressing dorsolateral striatum neurons. J Neurosci 35, 56255639, doi:10.1523/JNEUROSCI.4997-14.2015 (2015).

144 Bowers, S. L., Bilbo, S. D., Dhabhar, F. S. \& Nelson, R. J. Stressor-specific alterations in corticosterone and immune responses in mice. Brain Behav Immun 22, 105-113, doi:10.1016/j.bbi.2007.07.012 (2008).

145 Nicholson-Tomishima, K. \& Ryan, T. A. Kinetic efficiency of endocytosis at mammalian CNS synapses requires synaptotagmin I. Proc Natl Acad Sci U S A 101, 16648-16652, doi:10.1073/pnas.0406968101 (2004).

146 Vendruscolo, L. F. et al. Corticosteroid-dependent plasticity mediates compulsive alcohol drinking in rats. J Neurosci 32, 7563-7571, doi:10.1523/JNEUROSCI.0069-12.2012 (2012).

147 Lagstrom, O., Danielsson, K., Soderpalm, B., Ericson, M. \& Adermark, L. Voluntary Ethanol Intake Produces Subregion-Specific Neuroadaptations in Striatal and Cortical Areas of Wistar Rats. Alcohol Clin Exp Res 43, 803-811, doi:10.1111/acer.14014 (2019).

148 Liu, J., Lewohl, J. M., Harris, R. A., Dodd, P. R. \& Mayfield, R. D. Altered gene expression profiles in the frontal cortex of cirrhotic alcoholics. Alcohol Clin Exp Res 31, 1460-1466, doi:10.1111/j.15300277.2007.00444.x (2007).

149 Prager, E. M., Bergstrom, H. C., Wynn, G. H. \& Braga, M. F. The basolateral amygdala gammaaminobutyric acidergic system in health and disease. J Neurosci Res 94, 548-567, doi:10.1002/jnr.23690 (2016).

150 Terburg, D. et al. Hypervigilance for fear after basolateral amygdala damage in humans. Transl Psychiatry 2, e115, doi:10.1038/tp.2012.46 (2012).

151 Nuss, P. Anxiety disorders and GABA neurotransmission: a disturbance of modulation. Neuropsychiatr Dis Treat 11, 165-175, doi:10.2147/NDT.S58841 (2015).

152 McGinnis, M. M., Parrish, B. C., Chappell, A. M., Alexander, N. J. \& McCool, B. A. Chronic Ethanol Differentially Modulates Glutamate Release from Dorsal and Ventral Prefrontal Cortical Inputs onto Rat Basolateral Amygdala Principal Neurons. eNeuro 7, doi:10.1523/ENEURO.0132-19.2019 (2020).

153 Hopf, F. W. \& Lesscher, H. M. Rodent models for compulsive alcohol intake. Alcohol 48, 253-264, doi:10.1016/j.alcohol.2014.03.001 (2014).

154 Burns, L. \& Teesson, M. Alcohol use disorders comorbid with anxiety, depression and drug use disorders. Findings from the Australian National Survey of Mental Health and Well Being. Drug Alcohol Depend 68, 299-307, doi:10.1016/s0376-8716(02)00220-x (2002).

155 Hasin, D. S., Stinson, F. S., Ogburn, E. \& Grant, B. F. Prevalence, correlates, disability, and comorbidity of DSM-IV alcohol abuse and dependence in the United States: results from the National Epidemiologic Survey on Alcohol and Related Conditions. Arch Gen Psychiatry 64, 830-842, doi:10.1001/archpsyc.64.7.830 (2007).

156 Heilig, M. et al. Reprogramming of mPFC transcriptome and function in alcohol dependence. Genes Brain Behav 16, 86-100, doi:10.1111/gbb.12344 (2017).

157 Park, J., Wood, J., Bondi, C., Del Arco, A. \& Moghaddam, B. Anxiety Evokes Hypofrontality and Disrupts Rule-Relevant Encoding by Dorsomedial Prefrontal Cortex Neurons. J Neurosci 36, 3322-3335, doi:10.1523/JNEUROSCI.4250-15.2016 (2016).

158 Quirk, G. J., Garcia, R. \& Gonzalez-Lima, F. Prefrontal mechanisms in extinction of conditioned fear. Biol Psychiatry 60, 337-343, doi:10.1016/j.biopsych.2006.03.010 (2006).

159 Burgos-Robles, A., Vidal-Gonzalez, I. \& Quirk, G. J. Sustained conditioned responses in prelimbic prefrontal neurons are correlated with fear expression and extinction failure. J Neurosci 29, 84748482, doi:10.1523/JNEUROSCI.0378-09.2009 (2009).

160 Quirk, G. J. \& Mueller, D. Neural mechanisms of extinction learning and retrieval. Neuropsychopharmacology 33, 56-72, doi:10.1038/sj.npp.1301555 (2008).

161 Sun, Y., Gooch, H. \& Sah, P. Fear conditioning and the basolateral amygdala. F1000Res 9, doi:10.12688/f1000research.21201.1 (2020).

162 Arruda-Carvalho, M. \& Clem, R. L. Pathway-selective adjustment of prefrontal-amygdala transmission during fear encoding. J Neurosci 34, 15601-15609, doi:10.1523/JNEUROSCI.2664-14.2014 (2014).

163 Sierra-Mercado, D., Padilla-Coreano, N. \& Quirk, G. J. Dissociable roles of prelimbic and infralimbic cortices, ventral hippocampus, and basolateral amygdala in the expression and extinction of conditioned fear. Neuropsychopharmacology 36, 529-538, doi:10.1038/npp.2010.184 (2011). 
164 Likhtik, E., Stujenske, J. M., Topiwala, M. A., Harris, A. Z. \& Gordon, J. A. Prefrontal entrainment of amygdala activity signals safety in learned fear and innate anxiety. Nat Neurosci 17, 106-113, doi:10.1038/nn.3582 (2014).

165 Diehl, M. M. et al. Divergent projections of the prelimbic cortex bidirectionally regulate active avoidance. Elife 9, doi:10.7554/eLife.59281 (2020).

166 Vianna, D. M., Graeff, F. G., Brandao, M. L. \& Landeira-Fernandez, J. Defensive freezing evoked by electrical stimulation of the periaqueductal gray: comparison between dorsolateral and ventrolateral regions. Neuroreport 12, 4109-4112, doi:10.1097/00001756-200112210-00049 (2001).

167 Vianna, D. M., Landeira-Fernandez, J. \& Brandao, M. L. Dorsolateral and ventral regions of the periaqueductal gray matter are involved in distinct types of fear. Neurosci Biobehav Rev 25, 711-719, doi:10.1016/s0149-7634(01)00052-5 (2001).

168 Sewards, T. V. \& Sewards, M. A. Fear and power-dominance drive motivation: neural representations and pathways mediating sensory and mnemonic inputs, and outputs to premotor structures. Neurosci Biobehav Rev 26, 553-579, doi:10.1016/s0149-7634(02)00020-9 (2002).

169 Dines, M. \& Lamprecht, R. The Role of Ephs and Ephrins in Memory Formation. Int J Neuropsychopharmacol 19, doi:10.1093/ijnp/pyv106 (2016).

170 Sudhof, T. C. Neuroligins and neurexins link synaptic function to cognitive disease. Nature 455, 903911, doi:10.1038/nature07456 (2008).

171 Chen, F. et al. Dysfunction of the SNARE complex in neurological and psychiatric disorders. Pharmacol Res 165, 105469, doi:10.1016/j.phrs.2021.105469 (2021).

172 Schafe, G. E., Nader, K., Blair, H. T. \& LeDoux, J. E. Memory consolidation of Pavlovian fear conditioning: a cellular and molecular perspective. Trends Neurosci 24, 540-546, doi:10.1016/s01662236(00)01969-x (2001).

173 Rao-Ruiz, P. et al. Engram-specific transcriptome profiling of contextual memory consolidation. Nat Commun 10, 2232, doi:10.1038/s41467-019-09960-x (2019).

174 Chen, M. B., Jiang, X., Quake, S. R. \& Sudhof, T. C. Persistent transcriptional programmes are associated with remote memory. Nature 587, 437-442, doi:10.1038/s41586-020-2905-5 (2020).

175 Patki, G., Solanki, N. \& Salim, S. Witnessing traumatic events causes severe behavioral impairments in rats. Int J Neuropsychopharmacol 17, 2017-2029, doi:10.1017/S1461145714000923 (2014).

176 Karlsson, C. et al. Proinflammatory signaling regulates voluntary alcohol intake and stress-induced consumption after exposure to social defeat stress in mice. Addict Biol 22, 1279-1288, doi:10.1111/adb.12416 (2017).

177 Croft, A. P., Brooks, S. P., Cole, J. \& Little, H. J. Social defeat increases alcohol preference of C57BL/10 strain mice; effect prevented by a CCKB antagonist. Psychopharmacology (Berl) 183, 163-170, doi:10.1007/s00213-005-0165-6 (2005).

178 van Erp, A. M. \& Miczek, K. A. Persistent suppression of ethanol self-administration by brief social stress in rats and increased startle response as index of withdrawal. Physiol Behav 73, 301-311, doi:10.1016/s0031-9384(01)00458-9 (2001).

179 Warren, B. L. et al. Neurobiological sequelae of witnessing stressful events in adult mice. Biol Psychiatry 73, 7-14, doi:10.1016/j.biopsych.2012.06.006 (2013).

180 Ebner, K., Wotjak, C. T., Landgraf, R. \& Engelmann, M. Forced swimming triggers vasopressin release within the amygdala to modulate stress-coping strategies in rats. Eur J Neurosci 15, 384-388, doi:10.1046/j.0953-816x.2001.01869.x (2002).

181 Salome, N., Stemmelin, J., Cohen, C. \& Griebel, G. Differential roles of amygdaloid nuclei in the anxiolytic- and antidepressant-like effects of the V1b receptor antagonist, SSR149415, in rats. Psychopharmacology (Berl) 187, 237-244, doi:10.1007/s00213-006-0424-1 (2006).

182 Nelson, B. S., Sequeira, M. K. \& Schank, J. R. Bidirectional relationship between alcohol intake and sensitivity to social defeat: association with Tacr1 and Avp expression. Addict Biol 23, 142-153, doi:10.1111/adb.12494 (2018).

183 Harper, K. M. et al. Amygdala Arginine Vasopressin Modulates Chronic Ethanol Withdrawal AnxietyLike Behavior in the Social Interaction Task. Alcohol Clin Exp Res 43, 2134-2143, doi:10.1111/acer.14163 (2019).

184 Murgatroyd, C. et al. Impaired repression at a vasopressin promoter polymorphism underlies overexpression of vasopressin in a rat model of trait anxiety. J Neurosci 24, 7762-7770, doi:10.1523/JNEUROSCI.1614-04.2004 (2004). 
185 Shalev, I. et al. Vasopressin needs an audience: neuropeptide elicited stress responses are contingent upon perceived social evaluative threats. Horm Behav 60, 121-127, doi:10.1016/j.yhbeh.2011.04.005 (2011).

186 Brunnlieb, C., Munte, T. F., Tempelmann, C. \& Heldmann, M. Vasopressin modulates neural responses related to emotional stimuli in the right amygdala. Brain Res 1499, 29-42,

doi:10.1016/j.brainres.2013.01.009 (2013).

187 Zink, C. F., Stein, J. L., Kempf, L., Hakimi, S. \& Meyer-Lindenberg, A. Vasopressin modulates medial prefrontal cortex-amygdala circuitry during emotion processing in humans. J Neurosci 30, 7017-7022, doi:10.1523/JNEUROSCI.4899-09.2010 (2010).

188 Liu, J. J., Lou, F., Lavebratt, C. \& Forsell, Y. Impact of Childhood Adversity and Vasopressin receptor 1a Variation on Social Interaction in Adulthood: A Cross-Sectional Study. PLoS One 10, e0136436, doi:10.1371/journal.pone.0136436 (2015).

189 Windle, R. J., Shanks, N., Lightman, S. L. \& Ingram, C. D. Central oxytocin administration reduces stressinduced corticosterone release and anxiety behavior in rats. Endocrinology 138, 2829-2834, doi:10.1210/endo.138.7.5255 (1997).

190 Olff, M. et al. Social support, oxytocin, and PTSD. Eur J Psychotraumatol 5, 26513, doi:10.3402/ejpt.v5.26513 (2014).

191 (SAMHSA)., S. A. a. M. H. S. A. 2019 National Survey on Drug Use and Health (NSDUH). < https://www.samhsa.gov/data/sites/default/files/cbhsqreports/NSDUHDetailedTabs2018R2/NSDUHDetTabsSect2pe2018.htm\#tab2-1b > (2019).

$192 \mathrm{Xu}, \mathrm{W}$. et al. Distinct neuronal coding schemes in memory revealed by selective erasure of fast synchronous synaptic transmission. Neuron 73, 990-1001, doi:10.1016/j.neuron.2011.12.036 (2012).

193 Grant, B. F. et al. Epidemiology of DSM-5 Alcohol Use Disorder: Results From the National Epidemiologic Survey on Alcohol and Related Conditions III. JAMA Psychiatry 72, 757-766, doi:10.1001/jamapsychiatry.2015.0584 (2015).

194 Robinson, T. E. Neuroscience. Addicted rats. Science 305, 951-953, doi:10.1126/science.1102496 (2004).

195 Steimer, T. Animal models of anxiety disorders in rats and mice: some conceptual issues. Dialogues Clin Neurosci 13, 495-506 (2011).

196 Abbondanza, C. et al. The retinoblastoma-interacting zinc-finger protein RIZ is a downstream effector of estrogen action. Proc Natl Acad Sci U S A 97, 3130-3135, doi:10.1073/pnas.050015697 (2000).

197 Carling, T. et al. A histone methyltransferase is required for maximal response to female sex hormones. Mol Cell Biol 24, 7032-7042, doi:10.1128/MCB.24.16.7032-7042.2004 (2004).

198 Palanza, P. \& Parmigiani, S. How does sex matter? Behavior, stress and animal models of neurobehavioral disorders. Neurosci Biobehav Rev 76, 134-143, doi:10.1016/j.neubiorev.2017.01.037 (2017).

199 Takahashi, A. et al. Establishment of a repeated social defeat stress model in female mice. Sci Rep 7, 12838, doi:10.1038/s41598-017-12811-8 (2017).

200 Finnell, J. E. et al. Essential Role of Ovarian Hormones in Susceptibility to the Consequences of Witnessing Social Defeat in Female Rats. Biol Psychiatry 84, 372-382, doi:10.1016/j.biopsych.2018.01.013 (2018).

201 Lu, Y. et al. Epigenetic regulation in human cancer: the potential role of epi-drug in cancer therapy. Mol Cancer 19, 79, doi:10.1186/s12943-020-01197-3 (2020).

Figures were created with BioRender.com 


\section{Papers}

The papers associated with this thesis have been removed for copyright reasons. For more details about these see:

http://urn.kb.se/resolve?urn=urn:nbn:se:liu:diva-174707 


\section{FACULTY OF MEDICINE AND HEALTH SCIENCES}

Linköping University Medical Dissertation No. 1767, 2021

Department of Biomedical and Clinical Sciences

\section{Linköping University}

SE-581 83 Linköping, Sweden

\section{www.liu.se}

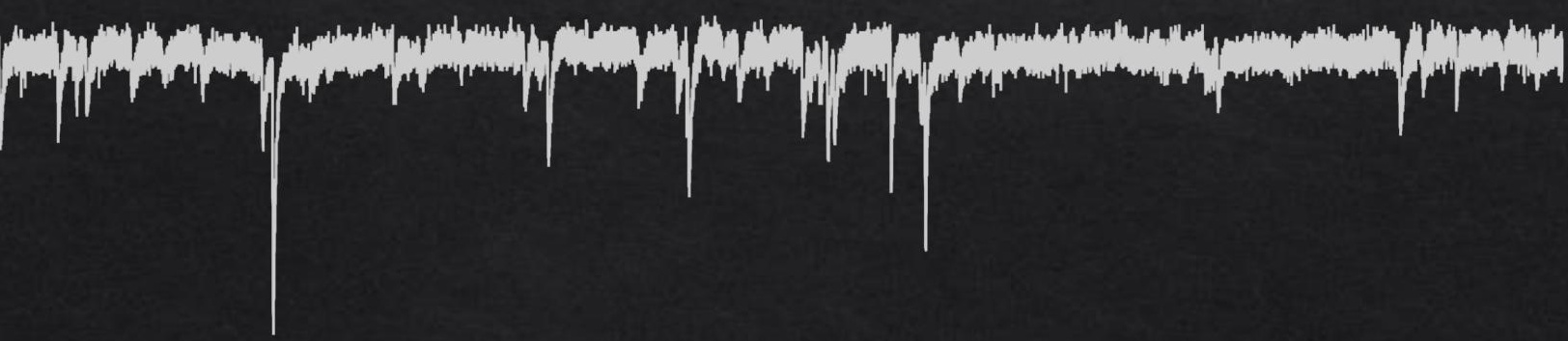

